\title{
ACERCA DE LA MOTIVACIÓN DE LOS HECHOS EN LA SENTENCIA PENAL *
}

«...la justicia que depende de la verdad de los hechos»

M. Murena ${ }^{1}$

\section{INTRODUCCIÓN}

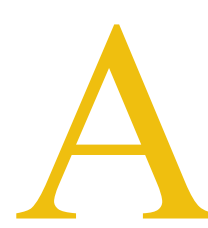

juicio de Calamandrei, «la motivación constituye el signo más importante y típico de la "racionalización" de la función judicial»². Y, aunque no siempre en la historia la imposición del deber de motivar ha respondido al interés de conferir mayor racionalidad en el más amplio sentido de racionalidad democrática- al ejercicio del poder de los jueces ${ }^{3}$, lo cierto es que la resolución motivada, como resultado, sí ha operado objetivamente en favor de ese interés.

En efecto, por modesto que fuere el alcance dado al deber de motivar, el simple hecho de ampliar el campo de lo observable de la decisión, no sólo para los destinatarios directos de la misma, sino al mismo tiempo e inevitablemente para terceros, comporta para el autor de aquélla la exigencia de un principio o

${ }^{*}$ Este trabajo constituye un desarrollo y reelaboración de la intervención del autor en el curso del Consejo General del Poder Judicial sobre «La sentencia penal» celebrado en 1992.

${ }^{1}$ Tratado de las obligaciones del juez, por Maximiliano Murena, jurisconsulto napolitano, traducido del italiano al francés; y de éste al idioma castellano por D. Cristóbal Cladera. Madrid MDCCLXXXV, por D. Plácido Barco López, p. 66.

${ }^{2}$ P. Calamandrei, Proceso y democracia. Trad. de H. Fix Zamudio, Ejea, Buenos Aires, 1960, p. 115 .

${ }^{3}$ Es un ejemplo emblemático al respecto la pragmática napolitana de Fernando IV, de 22 de septiembre de 1774, que imponía a los jueces el deber de motivar, en este caso entendido en el sentido de expresar la norma aplicada; y que, más que democratizar el ejercicio de la jurisdicción, que hubiera sido impropio de un régimen autocrático, buscaba reforzar la centralización del poder, neutralizando uno de tantos particularismos feudales. (Sobre este episodio puede verse: F. Cordero, Riti e sapienza del diritto. Laterza, Roma-Bari, 1981, pp. 663-666). 
un plus de justificación del acto ${ }^{4}$; y una mayor exposición de éste a la opinión.

Lo prueba la histórica reacción de los jueces napolitanos ${ }^{5}$, sobre la intensidad de cuya resistencia a la pragmática de Fernando IV en favor de un incipiente principio de motivación ilustra el dato de que, años después, tuvo que ser abolida. Pero más en general, las propias atormentadas vicisitudes pretéritas y actuales del jugement motivé, que, aunque dan sobrada razón a Cordero en su afirmación de que «el hermetismo es connatural al narcisismo togado ${ }^{6}$, apuntan a un más allá, o un antes, que tiene que ver con la propia naturaleza del poder en general.

No cabe duda de que es así cuando se trata de un poder, de cualquier modo, absoluto; porque «el estado se desequilibra y debilita» si «los hombres se consideran capacitados para debatir y disputar entre sí acerca de los mandatos» ${ }^{7}$ de aquél. Pero tampoco el estado democrático ${ }^{8}$, se ve libre de esa forma de atavismo, seguramente genético. De ello da buena cuenta la conocida propensión al secreto y, en el terreno que nos ocupa, la lectura y la práctica habitualmente reductivas del imperativo de motivar las resoluciones judiciales cuando éste ha hecho acto de presencia en algún texto legal ${ }^{9}$.

Con todo, es una evidencia que la constitucionalización del deber de motivar las sentencias (art. 120,3), a partir de 1978 y por

${ }^{4}$ «El motivo responde a la pregunta ¿por qué? Tiene, por tanto, una función de explicación; pero la explicación (...) al menos en los contextos en los que motivo significa razón, consiste en hacer claro, en hacer inteligible, en hacer comprender». (P. Ricoeur, El discurso de la acción. Trad. de P.

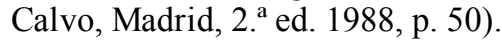

${ }^{5}$ «Scatena un putiferio la riforma», escribe gráficamente al respecto Cordero, en Procedura penale. Giuffrè, Milán, 1991, p. 819.

${ }^{6}$ Op. ult. cit., p. 816.

${ }^{7}$ T. Hobbes, Leviatán. Trad. de C. Mellizo, Alianza Editorial, Madrid, 1989, p. 258.

${ }^{8}$ Cfr. al respecto: F. J. De Lucas Martín, «Democracia y transparencia. Sobre poder, secreto y publicidad», Anuario de Filosofía del Derecho, 1990, pp. 131 y ss.

${ }^{9}$ Entre nosotros, como es bien notorio, sólo en los últimos años, y trabajosamente, ha empezado a abrirse camino una cierta cultura democrática de la motivación. Con todo, la misma tiende a manifestarse de forma casi exclusiva en las sentencias y, dentro de éstas, preferentemente en la fundamentación jurídica.

Así, no son infrecuentes resoluciones como el auto de un juzgado de instrucción de Madrid, que motivaba la denegación de reformar otro previo de archivo de las actuaciones - fundado a su vez en que «los hechos no revisten caracteres de infracción penal»-, en «que las razones alegadas por la parte recurrente no alcanzan a desvirtuar el criterio que movió al instructor para dictar el auto que hoy se impugna...». 
primera vez en nuestra experiencia histórica ${ }^{10}$, ha significado un cambio de paradigma.

En efecto, en nuestro país, como en otros del entorno, la primera aparición del deber de motivar responde prioritariamente a exigencias de carácter político: se busca en él una garantía frente al arbitrio ${ }^{11}$.

Que es así y que hay un sentir al respecto más o menos generalizado lo pone de manifiesto la circunstancia de que esa línea argumental encuentre eco, en la primera mitad del siglo XIX, en obras de carácter eminentemente práctico, como la de Verlanga Huerta. Para este autor, «el dar los motivos de la sentencia, prueba por lo menos un sagrado respeto a la virtud de la justicia, y una sumisión absoluta a la ley (...). El motivar los fallos tiene ya algo de publicidad, y he aquí una de las ventajas de esta práctica. Dispensar al juzgador de razonar los decretos que dé sobre la hacienda, vida y honor de los ciudadanos, es autorizarle tácitamente para ejercer la arbitrariedad...» ${ }^{12}$.

No es tan claro, sin embargo, que esa dimensión de naturaleza político-general, por así decir erga omnes, de la sentencia, resulte eficazmente traducida en la legislación ordinaria. Por el contrario, parece que en ésta hay más bien una tendencia a entender el deber de motivar como pura exigencia técnica «endoprocesal» ${ }^{13}$, que

${ }^{10}$ Sobre los antecedentes del tema, en general, cfr.: M. Ortells Ramos, «Origen histórico del deber de motivar las sentencias», en Revista de Derecho Procesal Iberoamericana, 1977, pp. 899 y ss. También F. Ranieri, «El estilo judicial español y su influencia en la Europa del antiguo régimen», en España y Europa, un pasado jurídico común (Actas del I Simposio Internacional del instituto de Derecho Común, Murcia 26-28 de marzo de 1985), ed. a cargo de A. Pérez Martín, Universidad de Murcia, Murcia, 1986, pp. 101 y ss.

${ }^{11}$ Así, T. Sauvel, al referirse a la obra de la Revolución y su reflejo en la materia de que tratamos, pone de manifiesto la existencia de una opinión crítica generalizada en contra de la famosa fórmula «pour les cas résultant du procès», con que los tribunales del antiguo régimen fundaban sus decisiones; y la demanda de que éstas fueran siempre motivadas («Histoire du jugement motivé», en Revue du Droit Public et de la Science Politique en France et a l'Etranger, 1955, pp. 43-44).

Para nuestro país es expresivo el testimonio del diputado en las Cortes de Cádiz, José de Cea, que presentó un proyecto de decreto propugnando que para «quitar la malicia, fraude y arbitrariedad todo pretexto, y asegurar en el público la exactitud, celo y escrupulosidad de los magistrados... en toda decisión... se expongan las razones, causas y fundamentos en que se apoyan... para... las decisiones se funden... sobre el texto expreso de las leyes...» (cit. por Ortells Ramos, en op. cit., p. 905).

${ }^{12}$ F. Verlanga Huerta, Procedimiento en materia criminal. Tratado que comprende todas las reglas procesivas de dicha materia respecto a la jurisdicción ordinaria, tomo I. Librería de Ríos, Madrid, 1842, p. 426.

13 Así lo entiende para Italia E. Amodio, voz «Motivazione della sentenza penale», Enciclopedia del Diritto, vol. XXVIL Giuffrè, Milán, 1977, p. 186). 
mira a hacer posible a las partes el ejercicio de la eventual impugnación.

Una confirmación de esta hipótesis puede hallarse para nuestro país en la forma como la Ley de Enjuiciamiento Criminal trata el tema. En efecto, una vez excluido el control casacional de los hechos, el legislador se despreocupa de imponer al juez en la redacción de la sentencia (art. 142,2) alguna cautela en garantía de la efectividad del imperativo de vinculación de la convicción sobre aquéllos al resultado de «las pruebas practicadas en el juicio», contenido el art. 741.

Así lo hizo notar Gómez Orbaneja, a cuyo entender, la expresión de ese último precepto «sugiere indebidamente una operación íntima y secreta de que no hubiese que dar cuenta ${ }^{14}$.

Es cierto que una Orden de 5 de abril de 1932 trató de salir al paso de la «práctica viciosa» en que generalmente se traducía la interpretación del art. 142 por los tribunales. Pero sólo porque ello hacía «prácticamente imposible el normal desenvolvimiento del recurso de casación». De este modo, la preocupación ministerial se circunscribía a la obtención de una adecuada expresión del resultado probatorio y de un correcto deslinde entre la quaestio facti y la quaestio iuris, en tanto que elementos necesarios para el juego del control de legitimidad. Pero nada parecido, en el texto de la orden, a la exigencia de que en la sentencia se hicieran explícitos los patrones de valoración y el rendimiento conforme a ellos de cada medio probatorio en el caso concreto. Lo que, en último término, constituye una ulterior confirmación del criterio antes expuesto.

Este mismo criterio encuentra también apoyo autorizado en alguna jurisprudencia de la Sala Segunda del Tribunal Supremo. Seguramente en ningún caso en términos tan llamativos como lo hizo la sentencia de 10 de febrero de 1978 (ponente Vivas Marzal), al declarar que «el tribunal debe abstenerse de recoger en su narración histórica la resultancia aislada de las pruebas practicadas... y, con mucho mayor motivo, el análisis o valoración de las mismas, totalmente ocioso e innecesario dada la soberanía que la ley le concede para dicha valoración y que debe permanecer incógnita en la conciencia de los juzgadores y en el secreto de las deliberaciones»; añadiendo que «el tribunal no puede ni debe dar 249.

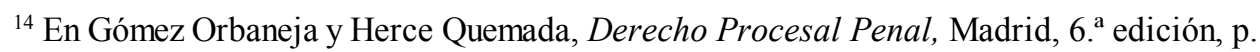


explicaciones del porqué llegó a las conclusiones fácticas...»» ${ }^{15}$.

${ }^{15}$ Tomo la cita de J. L. Vázquez Sotelo, Presunción de inocencia del imputado e intima convicción del tribunal. Bosch, Barcelona, 1984, p.507. El autor indica que la sentencia de instancia que fue en este caso el referente de la de casación 
Frente a este estado de cosas, la inclusión del deber de motivar en el art. 120,3 de la Constitución, precisamente dentro del título VI dedicado al «poder judicial», y en un precepto que consagra otras dos fundamentales garantías procesales: la publicidad y la oralidad, no puede dejar de ser significativa. Significativa y totalmente coherente, puesto que, como ha escrito Ferrajoli, estas últimas, junto con la de motivación, son "garantías de garantías», de carácter «instrumental», por tanto, pero condición sine qua non de la vigencia de las «primarias o epistemológicas» ${ }^{16}$. Del proceso penal, en general, como vehículo del derecho punitivo.

Es por ello que la motivación como mecanismo de garantía, en un diseño procesal del género del que se expresa en la Constitución de 1978, no puede limitar su funcionalidad al ámbito de las relaciones inter partes, asumiendo necesariamente una función extraprocesal ${ }^{17}$.

De esta función, y de la consiguiente inserción de la sentencia en un marco abierto, se deriva la apertura de un nuevo ámbito de relaciones, que tiene como sujetos, por un lado, al juez o tribunal, y, por otro, a la totalidad de los asociados, que se constituyen en destinatarios también de la sentencia e interlocutores de aquéllos.

$\mathrm{Y}$ esto a su vez implica exigencias de naturaleza formal, pero de intenso contenido político-garantista. Porque la sentencia, al (y para) trascender la dimensión burocrática, demanda un estilo diverso del convencional, que tendría que concretarse, en primer lugar, en un lenguaje diferente, adecuado para el nuevo tipo de comunicación, y, probablemente, también en una nueva estructura.

En este contexto la quaestio facti y su tratamiento en la sentencia, más que cobrar otro sentido, pueden llegar a adquirir el reconocimiento explícito del que efectivamente tienen: que es ser el momento de ejercicio del poder judicial por antonomasia. Puesto que es en la reconstrucción o en la elaboración de los hechos donde el juez es más soberano, más difícilmente controlable, y donde, por ende, puede ser -como ha sido y en no pocas ocasiones sigue siendo- más arbitrario.

debió perderse en un injustificado relato de incidencias procesales irrelevantes para el fallo, omitiendo, sin embargo, otros datos relevantes. Pero señala también que ese mismo criterio «tiene respaldo en otras muchísimas decisiones del mismo TS, aunque no siempre en términos tan contundentes» (p. 508).

${ }^{16}$ Éstas son la formalización de la acusación, la carga de la prueba y el derecho de defensa. (L. Ferrajoli, Diritto e ragione. Teoria del garantismo penale. Laterza, Roma-Bari, 1. a edición 1989, pp. 681 y 632).

${ }^{17}$ En este sentido M. Taruffo, «La fisonomia della sentenza in Italia», en Rivista Trimestrale di Diritto e Procedura Penale, 1986, p. 443. 
A tenor de las precedentes consideraciones, cabe preguntarse 
acerca del contenido de la motivación. Tradicionalmente se han perfilado dos propuestas. Una primera lo identifica con la «individualización del iter lógico-jurídico mediante el que el juez ha llegado a la decisión» ${ }^{18}$; una actividad de tipo prevalentemente descriptivo ${ }^{19}$.

Del anterior difiere el punto de vista que atribuye a la motivación un carácter más bien justificativo ${ }^{20}$, que opera como racionalización a posteriori ${ }^{21}$ de la decisión previamente tomada.

En contraste con esas posturas, que tratan de elucidar lo que la motivación es, Ferrajoli ha reclamado recientemente para la actividad motivadora del juez un estatuto esencialmente cognoscitivo, único que puede conferir a la decisión judicial legitimidad política y validez desde el punto de vista epistemológico y jurídico ${ }^{22}$. A este punto de vista haré referencia con algún pormenor más adelante.

\section{HECHOS}

Se ha escrito por un magistrado italiano ${ }^{23}$ que, del mismo modo que el burgués gentilhombre se sorprendió al conocer que hablaba en prosa, los jueces podrían también experimentar sorpresa si fueran plenamente conscientes de la densidad de las cuestiones epistemológicas y la notable complejidad de los procesos lógicos implícitos en el más elemental de los razonamientos de que habitualmente hacen uso.

La reflexión debe ir más allá porque, en tanto esa conciencia se produce, el discurso judicial -el jurídico-práctico en general-

${ }^{18} \mathrm{Al}$ respecto cfr. M. Taruffo, La Motivazione della sentenza civile. Cedam, Padua, 1975, p. 417.

${ }^{19}$ E. Amodio se ha referido a este punto de vista calificándolo de «falacia descriptivista», en cuya virtud «la motivación externa se convierte en una... descripción que tiene el único fin de hacer conocer lo que el juez ha elaborado "en su cabeza"» (en op. cit., p. 214).

${ }^{20}$ Así, también entre nosotros M. Atienza: «Los órganos jurisdiccionales o administrativos, no tienen por lo general, que explicar sus decisiones, sino que justificarlas». (En Las razones del Derecho. Teorías de la argumentación jurídica. Centro de Estudios Constitucionales, Madrid, 1991, p. 23).

${ }^{21}$ Así lo entendió Calamandrei, en op. cit., p. 125.

${ }^{22}$ En op. cit., p. 640.

${ }^{23}$ Cfr. E. Fassone, «Qualche altra rifiessione in tema di prova», en Questione giustizia, 3/1986, p. 721 .

En la reciente doctrina española, Luis Prieto Sanchís ha llamado especialmente la atención sobre la relevancia de la determinación de los hechos en la tarea interpretativa; poniendo de relieve cómo el margen de apreciación del juez es mayor a mayor proximidad procesal a la quaestio facti (cfr. Ideología e interpretación jurídica, Tecnos, Madrid, 1987, pp. 88 y ss.). 
en acto, no puede dejar de acusar negativamente ese lamentable operar sobre un cierto vacío epistemológico, ese acontecer de espaldas a un conocimiento efectivo de las propias reglas que lo constituyen.

Esta evidencia resulta todavía más patente en aquella vertiente del razonamiento judicial referida a lo que habitualmente se conoce como «lo fáctico», o «los hechos». Materia, por otro lado, particularmente descuidada en la mayoría de las teorías sobre la interpretación, y abandonada así en buena medida a la subjetividad del intérprete. Por eso Frank pudo escribir con toda razón que «esta "discrecionalidad en cuanto a los hechos" o "soberanía" virtualmente incontrolada e incontrolable, ha pasado por alto a la mayoría de los juristas» ${ }^{24}$.

Esa actitud ha tenido correspondencia en los textos positivos y, desde luego, en nuestra Ley de E. Criminal y en la jurisprudencia tradicional del Tribunal Supremo «exoneratoria de toda alegación sobre la convicción formada "en conciencia"»"

El tratamiento judicial que habitualmente reciben los hechos suele reflejar una consideración de los mismos como entidades naturales, previa y definitivamente constituidas desde el momento de su producción, que sólo se trataría de identificar en su objetividad. Lo escribió con mucha claridad Fenech, al referirse a ellos como «esos datos fríos de la realidad $\iota^{26}$.

Es decir, los datos como lo dado, o sea, esa «realidad o cualidad de alguna realidad, que es dada, y también que está dada, cuando se halla presente a un sujeto cognoscente sin la mediación de ningún concepto ${ }^{27}$.

Tal modo de existencia de los hechos para el juez haría posible de manera espontánea, sin mediaciones, una relación de total exterioridad, con el mínimo de implicaciones subjetivas.

Pero lo cierto es que el hecho puro del positivismo filosófico decimonónico no parece que exista como tal; y, en consecuencia, tampoco caben «los juicios de hecho entendidos como simples constataciones del "dato bruto "» ${ }^{28}$.

${ }^{24}$ J. Frank, Derecho e incertidumbre. Trad. de C. M. Bidegain, revisada por G. R. Carrió, Centro Editor de América Latina, Buenos Aires, 1968, p. 70. 1976, p. 325.

${ }^{25}$ L. Pietro-Castro y E. Gutiérrez de Cabiedes, Derecho Procesal Penal. Tecnos, Madrid,

${ }^{26}$ M. Fenech Navarro, Enjuiciamiento y, sentencia penal, Discurso inaugural del año académico 1971-72. Universidad de Barcelona, 1971, p. 51.

${ }^{27}$ J. Ferrater Mora, voz «Dado», Diccionario de Filosofía. Alianza Editorial, Madrid, 1979, vol. 1, p. 705 .

${ }^{28}$ G. Ubertis, Fatto e valore nel sistema probatorio penale. Giuffrè, Milán, 1979, p. 25. 
Por el contrario, en la moderna filosofía de la ciencia, tiene carta de naturaleza la idea de que se da «cierta intimidad conceptual entre lo que consideramos hechos y el lenguaje en que los afirmamos, o al menos entre los hechos y los tipos de entidad lógica que designamos como "enunciados" (...). Los hechos son aquello que afirman los enunciados verdaderos $\rangle^{29}$.

Este nuevo paradigma, al ofrecer una visión diferente del proceso cognoscitivo, revela también un distinto modo de relación entre el sujeto que trata de conocer y el segmento de experiencia sobre el que proyecta su interés. Y en nuestro caso, entre el juez, los hechos probatorios y el thema probandi.

Así resulta que el juez se entiende no directamente con los hechos como tales, sino con proposiciones relativas a hechos, con «representaciones cognoscitivas» que denotan algo acontecido en el mundo real ${ }^{30}$. Lo que, bajo su apariencia de obviedad, tiene implicaciones prácticas de extraordinaria relevancia que no pueden pasar desapercibidas.

Éstas son, en primer lugar, que sobre el proceso de conocimiento relativo a los hechos, al estar también mediado por el lenguaje ${ }^{31}$-«el lenguaje y la situación son

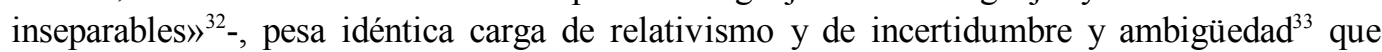
en todos los demás casos en que esa mediación tiene lugar. Esto es importante porque las mismas peculiaridades («ambigüedad», «textura abierta», «zonas de penumbra») que se predican de los enunciados deónticos suelen encontrarse también presentes en los enunciados que se expresan en lenguaje observacional; por más que éstos hayan de tener normalmente como referente entidades connotadas por un menor nivel de abstracción. Si como dice Echevarría, «la observación científica no es inmediata ni ingenua», sino que «está cargada conceptualmente ${ }^{34}$, cuánto más cargada de todo (preconceptos, prejuicios, etc.) no lo ha de estar

${ }^{29}$ N. R. Hanson, Patrones de descubrimiento. Observación y explicación. Trad. de E. García Camarero y A. Montesinos. Alianza Editorial, Madrid, 2. ${ }^{a}$ ed, 1985, pp. 16-17.

${ }^{30}$ T. A. Van Dijk, Estructuras y funciones del discurso. Trad. M. Gann y M. Mur, Siglo XXI Editores, 7. a ed., México, 1991, p. 81.

${ }^{31}$ Cfr. al respecto A. Ruiz Miguel, «Creación y aplicación en la decisión judicial», Anuario de Filosofía del Derecho, 1984 (separata), p. 12.

${ }^{32}$ M. Stubbs, Análisis del discurso. Análisis sociolingüistico del lenguaje natural. Trad. de C. González, Alianza Editorial, Madrid, 1983, p. 17.

${ }^{33}$ Lo expresó muy bien Frank: «Hay también, una ambigüedad perturbadora en la palabra "hecho". Los "hechos" son ambas cosas: "subjetivos" y "objetivos"». (En op. cit., p. 69).

${ }^{34} \mathrm{~J}$. Echevarría, Introducción a la metodología de la ciencia. La filosofía de la ciencia en el siglo XX. Barcanova, Barcelona, 1989, p. 70. 
una observación que suele acusar marcadísimas implicaciones emotivas, puesto que se traslada al proceso por la vía, siempre contaminada ${ }^{35}$, de las impresiones de testigos: terceros afectados/ interesados o moralmente concernidos por el tema del juicio ${ }^{36}$. Impresiones adquiridas, las más de las veces, espontáneamente en el curso de la vida ordinaria y, desde luego, sin el distanciamiento crítico que por lo común acompaña a la actividad cognoscitiva de los científicos; tan cautos, sin embargo, como se ha visto, al evaluar la posible objetividad de su conocimiento.

Por otra parte, en el caso del juez, esa mediación discursiva se da no como mera descripción aséptica de lo que ya existe al margen de la actividad del operador; sino como proceso de construcción del supuesto de hecho, construcción a la que el juez contribuye activamente, desde dentro. $\mathrm{Y}$ en ella está presente toda la carga de subjetivismo que acompaña a cualquier actividad interpretativa.

De aquí se deriva, pues, la exigencia de un control y una tensión hacia la adquisición del máximo de consciencia posible de todos los factores y contenidos de memoria que inciden sobre la propia actividad, que no tendría que ser menor que el que, más o menos pacíficamente, se acepta debe darse en la que habitualmente se conoce como actividad interpretativa. Es decir, la referida más directamente a las normas.

Del mismo modo que se ha dicho que los enunciados observacionales están cargados de teoría ${ }^{37}$, en el área de nuestro interés, tendría que decirse que los enunciados fácticos corren, además, el riesgo de estar cargados de derecho. Lo que constituye otra particularidad del proceso de conocimiento de los hechos a tener

${ }^{35}$ Interesantes indicaciones al respecto pueden encontrarse en J. J. Mira y M. Diges, «Procesos intervinientes en la evidencia de testigos», en F. J. Jiménez Burillo y M. Clemente (eds.), Psicología social y sistema penal. Alianza Editorial, Madrid, 1986, pp. 159 y ss.

${ }^{36}$ Como advierte T. A. Van Dijk, «la información se "recodifica" en información conceptual (...) la comprensión, el almacenamiento y la recuperación nunca son "puros", sino que también interactúan con todos los procesos "de pensamiento"» (...) por eso, «la reproducción es sobre todo producción». (Op. cit., pp. 90-92). Observación que es pertinente tanto para el caso del testigo y su forma de aportar material informativo al juez; como por lo que se refiere al tratamiento por éste de ese material.

${ }^{37}$ Son bien elocuentes al respecto las palabras de N.R. Hanson: «En cierto sentido, entonces, la visión es una acción que lleva una "carga teórica". La observación de $x$ está moldeada por un conocimiento previo de $x$. El lenguaje o las notaciones usadas para expresar lo que conocemos, y sin los cuales habría muy poco que pudiera reconocerse como conocimiento, ejercen también influencia sobre las observaciones». (En op. cit., p. 99). 
en cuenta, a la vez que apunta a otro riesgo de contaminación del mismo que no puede ser desatendido por el juez. En efecto, éste trabaja sobre una hipótesis, que es a su vez un punto de vista normativo, puesto que implica la afirmación de que en el caso concreto ha tenido lugar un hecho que es el previsto como supuesto base de un determinado precepto. Ahora bien, aun dentro de ese contexto, y aun en la perspectiva de la evaluación de esa hipótesis, la búsqueda de la verdad ha de ser ajena a otro interés que no sea precisamente ése. Hablo en este caso de interés como interés epistemológico que tiene expresión legal en el principio de presunción de inocencia, criterio-guía que aquí debe jugar como barrera impuesta al intérprete para, no obstante moverse en el marco de una hipótesis normativa, ser capaz de tratar el material empírico que se le suministra por terceros con el máximo de neutralidad y de distancia respecto del derecho sustantivo de eventual aplicación, evitando caer en el riesgo fácil de producir un caso $a d h o c^{38}$.

Situados en esta perspectiva es evidente que la actividad jurisdiccional presenta un especial grado de dificultad y su ejercicio plenamente responsable demanda un extraordinario nivel de autoconciencia sobre las peculiaridades de la misma.

La mayor parte de los enunciados, como señaló Russell, «está destinada a expresar hechos, que (salvo cuando se trate de hechos psicológicos) versarán acerca del mundo exterior» ${ }^{39}$. Esta circunstancia, en sí misma evidente, y la mayor dificultad de la captación y el tratamiento semántico de los «hechos psicológicos», unida a alguna particularidad de nuestro derecho probatorio, ha llevado a la jurisprudencia de la Sala Segunda del Tribunal Supremo a "atribuir a aquéllos la inapropiada naturaleza de "juicios de valor"», como ha puesto de manifiesto Beneytez Merino ${ }^{40}$.

Podrían citarse multitud de resoluciones ${ }^{41}$, pero sirva como

${ }^{38}$ Vale la pena recordar que hace ya casi 20 años L. Ferrajoli advertía del riesgo de forzar la realidad de los hechos, al establecer lo que de ellos resulta «jurídicamente relevante» en cada caso, que acecha siempre a la actividad jurisdiccional. Postulaba «criterios de valoración y de juicio "factualmente relevantes", es decir, adecuados al hecho considerado y tomado en su concreta realidad» («Magistratura Democratica e l'esercizio alternativo della funzione giudiziaria», en P. Barcellona (ed.) L'uso alternativo del diritto (I), Laterza, Roma-Bari, 1973, pp. 117-118).

${ }^{39}$ B. Russell, «La filosofía del atomismo lógico», en J. Muguerza (ed.), La concepción analítica de la filosofía I, Alianza Editorial, 1974, p. 145. (Cursiva mía).

${ }^{40}$ L. Beneytez Merino, «Juicio de valor y jurisprudencia», en Poder Judicial, 2. ${ }^{a}$ época, n. 19, septiembre de 1990, p. 15.

${ }^{41}$ En general (así, por ejemplo, Moyna Ménguez, 14 de junio de 1988) 
ejemplo una sentencia reciente, la de 30 de octubre de 1991 (ponente De Vega Ruiz), que expresa muy bien el punto de vista de referencia, cuando dice que «los juicios de valor suponen, en definitiva, una actividad de la mente y del raciocinio tendente a determinar la intencionalidad del agente o sujeto activo de la infracción en las distintas formas comisivas». Se trataría así de «juicios o "pareceres" de los jueces que indudablemente no deben ser incluidos en el factum de la sentencia por ser meras apreciaciones subjetivas». Es la razón por la que «es en los antecedentes de hecho en donde han de consignarse todas las circunstancias fácticas como soporte de la calificación jurídica, para dejar aquellos juicios de valor, inaprensibles por los sentidos, a la vía deductiva que, razonablemente, ha de estar inmersa en los fundamentos de derecho».

Sabido es que lo que busca la opción que expresa este criterio es extender el ámbito del control casacional a determinados aspectos de la sentencia ${ }^{42}$ : los relativos a la motivación sobre la intención y los motivos del agente; a los que se dé tratamiento de quaestio iuris, para hacerlos entrar dentro del ámbito material del recurso.

se reserva el calificativo de «hecho» para el ánimo o intención de matar, sólo cuando existe prueba directa; y se le considera «juicio axiológico o de valor» cuando la prueba es indirecta. O también, Puerta Luis, 27 de enero de 1992, tratándose de casos similares, se habla de «un hecho psicológico que debe inferirse, al faltar normalmente prueba directa...», con referencia al conocimiento de la procedencia ilícita de los bienes en un delito de receptación.

Así parece que la naturaleza de un dato fáctico, por más que de orden psicológico, dependería de factores externos, sobrevenidos, de índole procesal en este caso, como es el tipo de prueba.

${ }^{42}$ Esta posición tiene un autorizado exponente en E. Aguilera de Paz: «esa amplia potestad que la ley concede (alude al art. 741 de la Ley de Enjuiciamiento Criminal), se refiere tan sólo a la apreciación de las pruebas que tengan relación única y exclusivamente con los hechos de la causa y no las que se contraigan a los elementos morales o jurídicos relativos a ellos» porque «según se expuso en sentencia (del Tribunal Supremo) de 7 de abril de 1902, recaída en causa por delito de estafa, respecto a la apreciación del engaño» estaba justificado el cuestionamiento por la vía del recurso de casación, «supuesto que éste (el engaño) no es un hecho porque no pertenece a la esfera de los sucesos reales perceptibles por los sentidos, sino una mera deducción de carácter jurídico, mediante la cual se puede llegar a la averiguación de si el agente, al ejecutar los hechos estimados como ciertos en la sentencia, procedió o no con ánimo doloso y con voluntad contraria a derecho, infiriendo lógicamente por los mismos datos de la sentencia lo que hubiera de simulación o fraude en los actos por aquél realizados, pues, de lo contrario, se desnaturalizarían los preceptos de la ley y se haría ineficaz, en muchos casos, el recurso de casación» (Comentarios a la Ley de Enjuiciamiento Criminal, Editorial Reus, Madrid, 2. ${ }^{\text {ed. }}$ 1924, vol. V, pp. 558). 
Ocurre, sin embargo, que el fin perseguido que en apariencia reforzaría las garantías del enjuiciamiento, impone un precio objetivamente intolerable desde el punto de vista epistemológico, porque esa concepción niega o cuestiona implícitamente, o cuando menos siembra una seria confusión, acerca de la existencia como tal de una dimensión central de la conducta humana; y la posibilidad de acceder a un conocimiento racional de la misma.

Es decir, siguiendo el razonamiento expresado en el fallo que se cita, el único aspecto del comportamiento del que podría predicarse la existencia o inexistencia real, y susceptible por tanto de recibir el calificativo de fáctico, sería el integrado por los actos exteriores, perceptibles u observables de modo sensorial directo ${ }^{43}$. Sólo esa dimensión del comportamiento podría ser tratada mediante proposiciones asertivas, es decir, aquéllas de las que cabe afirmar verdad o falsedad, porque sus referentes serían los únicos con posibilidades objetivas de tener o no tener existencia real.

Por contraste, la determinación del carácter intencional o no intencional de la acción o acciones a examen, el elemento subjetivo del delito, resultaría desplazado a un ámbito discursivo diferente, el de los «juicios de valor» («bueno»/ «malo», «bonito»/ «feo»), que en cambio son proposiciones carentes de referente empírico. Los mismos, se expresan en lenguaje preceptivo, mediante enunciados que como tales no pueden ser ni verdaderos ni falsos, porque no corresponden a ningún hecho o circunstancia susceptible de verificación. No tienen contenido informativo que pueda ser susceptible de prueba o refutación, sino como su propio nombre indica, contenido simplemente valorativo.

Es cierto, con todo, que en ocasiones puede darse una cierta contigüidad entre lo que son propiamente aserciones relativas a hechos psíquicos y lo que constituyen juicios de valor, en sentido propio, acerca de los mismos. Así, cuando a la afirmación de que concurrió un determinado ánimo, que como tal será una proposición de carácter asertivo, se la acompaña de otra relativa, por ejemplo, a la consideración del mismo como de una especial perversidad.

A este respecto, vale la pena recordar que, como ha escrito Ayer, al valorar una acción «no estoy haciendo ninguna más amplia declaración acerca de ella. Sólo estoy poniendo de manifiesto la desaprobación moral que me merece. Es como si dijese

${ }^{43}$ Cabe advertir en este punto de vista una clara expresión del que los autores han designado como «inductivismo ingenuo» (cfr. A.F. Chalmers, ¿Qué es esa cosa llamada ciencia? Trad. de E. Pérez Sedeño y P. López Máñez, Siglo XXI Editores, pp. 12 y ss.). 
"Usted robó ese dinero", con un especial tono de horror, o como si lo escribiese añadiendo determinados signos de exclamación. El tono de los signos de exclamación no añaden nada a la significación literal de la oración. Sólo sirven para demostrar que la expresión está acompañada de ciertos sentimientos del que habla ${ }^{4}{ }^{4}$.

En consecuencia, visto el modo de operar de los «juicios de valor», no puede sostenerse, en el plano epistemológico, una diversidad de naturaleza entre la actividad cognoscitiva dirigida a establecer la existencia física de un determinado acto y la que tenga por objeto conocer la dimensión intencional del mismo, es decir, las caras externa e interna de un determinado comportamiento. Que el acceso a esta última pueda suponer un mayor grado de dificultad y que su determinación demande mayor cuidado o finura en la observación o en el análisis, no implica una distinta naturaleza de la actividad ${ }^{45}$.

Podrá decirse que, más allá de lo afortunado o desafortunado de algunas formulaciones, sería impensable que, por su obviedad, la existencia como tal de los factores intencionales pudiera resultar desconocida y menos negada por la tesis jurisprudencial de referencia. Pero aun admitiendo que así fuera, no por ello dejaría de resultar pertinente la crítica. Cuando menos por dos razones fundamentales.

La primera es que al atribuir a aquellas determinaciones el carácter de «juicio de valor», se opera el desplazamiento de las mismas a un campo especialmente connotado por la subjetividad menos controlable. El juez no vendrá obligado a expresar que -y por qué infiere que- algo ha contado con existencia real como parte o forma de un comportamiento ajeno, sino tan sólo a afirmar y en el mejor de los casos razonar su particular convicción, el porqué de la atribución de una determinada condición, que como tal (parece que en esa concepción) carecería de propia existencia empírica. Como recuerda Castilla del Pino, al tratarse

${ }^{44}$ A. J. Ayer, Lenguaje, verdad y lógica. Trad. de M. Suárez, Ediciones Martínez Roca, Barcelona, 1971, pp. 124-125.

45 «Decir que hay intencionalidad en la conducta es sugerir algo a la vez importante y que se presta con facilidad a equívocos. La formulación acierta al poner de relieve que la intencionalidad no es algo que queda "detrás" o "fuera" de la conducta. (...) Lo equívoco de la formulación reside en sugerir una "localización" de la intención, su confinamiento en un item de conducta determinado, como si se pudiera descubrir la intencionalidad mediante una inspección de movimientos. (...) La conducta adquiere su carácter intencional del hecho de ser vista por el propio agente o por un observador externo en una perspectiva más amplia, del hecho de hallarse situada en un contexto de objetivos y creencias». (G. H. von Wrigth, Explicación y comprensión. Trad. de L. Vega Reñón, Alianza Editorial, Madrid, 1980, p. 140). 
de una estimación, «ésta ya no pertenece al objeto sino al sujeto de la proposición» ${ }^{46}$.

La segunda es que se trata impropiamente como deducción a un razonamiento que no tiene ese carácter. Porque, en efecto, derivar de datos empíricos obtenidos mediante el análisis de los rasgos de un determinado comportamiento, que el mismo respondía a un cierto propósito: «la presencia en el agente de una determinada intención y (aun puede que) de una actitud cognoscitiva relativa a los medios conducentes al fin $\rangle^{47}$, tiene la condición de una inferencia inductiva. Como se sabe, el razonamiento deductivo presupone la existencia de una ley de valor universal, que permite, mediante la subsunción en ella de un supuesto particular y si se observan determinadas reglas lógicas, llegar a una conclusión, que es verdadera si lo son las premisas. Algo que no sucede en el razonamiento inductivo, en el que falta ese presupuesto y cuya conclusión, al ir más allá de las premisas, propicia una diferente calidad de conocimiento.

Esto último, aparte de privar a un discurso institucional de tanto relieve del exigible rigor, produce confusión acerca, no sólo del carácter de algunos aspectos de la conducta humana, sino también -y quizá sobre todo- de la naturaleza, del grado o la calidad de conocimiento, que el juez puede llegar a obtener por la vía de los impropiamente caracterizados como «juicios de valor» que, es evidente, nunca pasará de ser conocimiento probable y no deductivamente cierto.

Este aspecto de la cuestión goza a mi juicio de un relieve que no cabe desconocer, por lo importante que resulta que el juez tenga plena constancia del rendimiento de los instrumentos que utiliza, de la relatividad de los resultados, y que asuma su función como lo que debe ser realmente: antes que nada, una indagación cuidadosa sobre la existencia o inexistencia real de determinados datos de experiencia, en lo que, como luego veremos, nunca podrá contar con el auxilio de tranquilizad oras leyes de validez universal capaces de dar a sus inferencias consistencia axiomática.

Beneytez Merino, que como ya se anticipó, es autor de un

${ }^{46}$ C. Castilla del Pino, Introducción a la hermenéutica del lenguaje. Península, 1972, p. 178.

Como dice el autor las proposiciones estimativas «desempeñan una función ostensiva, no respecto del referente u objeto externo, o supuestamente externo (...) sino del referidor o hablante. $\mathrm{O}$ de otra forma, son palabras que expresan respecto del sujeto hablante, lo sepa o no lo sepa él». Por contraste con la proposición indicativa que es «un juicio de hecho verdadero o falso». (Enop. cit., pp. 101 y 103$)$.

${ }^{47}$ G. H. von Wrigth, op. cit., p. 134. 
encomiable esfuerzo - ¿el primero?- de clarificación en este campo, ha sugerido designar a los aludidos supuestos «juicios de valor», «juicios de inferencia» ${ }^{48}$. Propuesta que ha tenido una acogida peculiar -acogida peculiar, porque ahora, con frecuencia, simplemente se escribe «los juicios de valor o juicios de inferencia»-, tanto en la propia jurisprudencia de la Sala Segunda, como por algunos autores, para seguir sosteniendo -bajo diferente etiqueta- la misma actitud metodológica que se ha criticado $^{49}$. Pero, si se analiza el sentido de los términos, no parece que la opción sea en sí misma demasiado afortunada, como intento de descripción de la operación intelectual del juez que nos preocupa, puesto que juicio en este contexto es equivalente a «acto mental por medio del cual pensamos un enunciado»; o incluso «la afirmación o la negación de algo (de un predicado) con respecto a algo (un sujeto)» ${ }^{50}$. E inferencia no es sino «un proceso en el cual se llega a una proposición y se la afirma sobre la base de otra $\mathrm{u}$ otras proposiciones aceptadas como puntos de partida del proceso» ${ }^{51}$. Con lo que resulta que la expresión «juicio de inferencia» es anfibológica, puesto que podría designar lo mismo a la argumentación deductiva que a la inductiva, para significar algo tan impreciso e incluso tautológico como «juicio de razonamiento». Por ello, quizá sería lo más sencillo hablar simplemente de inferencia inductiva, porque cumple con la función descriptiva a que aspira todo acto de denotación; y porque no sugiere, como no debe sugerir, diferencia alguna de método en el modo de operar, por razón del objeto.

\section{RECONSTRUCCIÓN JUDICIAL DE LOS HECHOS: MODELOS DE REFERENCIA}

\section{El historiador}

La asimilación del trabajo del juez en la quaestio facti al del historiador, ha sido una

${ }^{48}$ En op. cit., p. 14.

${ }^{49}$ Así, en el caso de J. M. Luzón Cuesta, La presunción de inocencia ante la casación. Colex, Madrid, 1991, pp. 23-24. Y también, por ejemplo en la sentencia de la Segunda de 18 de noviembre de 1991 (ponente De Vega Ruiz).

${ }^{50}$ La primera es la aceptación, de entre todas las posibles, por la que se decanta J. Ferrater Mora, que también relaciona, entre otras varias, la segunda que se recoge (en op. cit., vol. II, pp. 1.821-1.822). 1962, p. 20.

${ }^{51}$ Así, I. M. Copi, Introducción a la lógica. Trad. de N. Miguez, Eudeba, Buenos Aires, 
constante, a partir de un conocido trabajo 
de Calamandrei ${ }^{52}$. Este autor señaló la existencia de importantes similitudes en el modo de proceder de ambos operadores: uno y otro estarían llamados a «indagar sobre los hechos del pasado y a declarar la verdad sobre los mismos» mediante «una obra de elección y construcción sobre "datos" preexistentes ${ }^{53}$. Ahora bien, esta constatación no podía ocultar algunas diferencias de relieve. Entre ellas y, sobre todo, la determinada por la situación estatutaria de pasividad del juez, que es garantía de una «imparcialidad desapasionada» que nunca estará al alcance del historiador: éste elige el tema y «en la elección del tema está ya la confesión de una preferencia y en la formulación del problema se encuentra ya implícito el criterio de la solución» ${ }^{54}$.

Por lo demás, sigue apuntando Calamandrei, mientras el juez tiene limitadas también normativamente las fuentes de conocimiento (es el caso, por ejemplo, de la «ciencia propia»), el historiador «no sabría resignarse nunca a cerrar los ojos a la verdad, únicamente porque el sendero que lo ha conducido hasta ella no esté indicado en los mapas oficiales» ${ }^{55}$. Además, en fin, donde éste último podría legítimamente expresar una actitud de incertidumbre, el juez estaría siempre obligado «a toda costa a llegar a una certeza oficial» ${ }^{56}$.

También Calogero se ocupó de señalar la analogía de ambos modelos; incidiendo en una particularidad metodológica y es que: «como el historiador, también el juez se encuentra con el hecho no como una realidad ya existente, sino como algo a reconstruir» ${ }^{57}$.

A pesar de lo sugestivo de la consideración comparativa, hay aspectos de la función del juez que condicionan desde fuera su forma de relación con los hechos y que no pueden dejar de apuntarse, aunque sea esquemáticamente. Nobili ${ }^{58}$ se ha manifestado en ese sentido, haciendo hincapié, en primer lugar, en el carácter eminentemente práctico de la orientación del juez. En efecto, el interés que mueve su actuación no es puramente gnoseológico, en la medida en que la averiguación de la verdad tiene que

${ }^{52} \mathrm{P}$. Calamandrei, «El juez y el historiador», en Estudios sobre el proceso civil. Trad. de S. Sentís Melendo, Editorial Bibliográfica Argentina, Buenos Aires, 1961, pp. 107 y ss.

${ }^{53}$ En op. cit., p. 107.

${ }^{54}$ En op. cit., p. 112.

${ }^{55}$ En op. cit., p. 114.

${ }^{56}$ En op. cit., p. 116.

${ }^{57} \mathrm{G}$. Calogero, La logica del giudice e il suo controllo in cassazione. Cedam, Padua, 2. ${ }^{\mathrm{a}} \mathrm{ed}$. 1964, p. 129.

${ }^{58}$ M. Nobili, Il principio del libero convincimento del giudice. Giuffrè, Milán, 1974, p. 49. 
ver con la resolución de un conflicto. Por otro lado, esa búsqueda está también interferida por el momento normativo. Y esto no sólo porque tenga que conducirse por cauces más o menos predeterminados, como se ha visto, sino porque la cuestión sobre la que el juez está obligado a pronunciarse, incluso en su dimensión fáctica, suele estar profundamente teñida de aspectos de valor y la indagación judicial siempre se da en función de una hipótesis necesariamente normativa.

Con todo, este juego de búsqueda de analogías y matices diferenciales deja prácticamente intacto un aspecto de fondo que, en este caso, es el que más interesa. Lo ha puesto de manifiesto Taruffo, al decir que así no se obtiene «ninguna indicación en torno al procedimiento en el que la investigación se exterioriza, ni precisa las características de lo que es objeto de la misma, ni aclara en qué consisten los datos en que se funda». Y es que, por esa vía se da «sólo en apariencia una solución al problema del juicio de hecho, mientras en realidad no se analiza la estructura lógica del procedimiento ${ }^{59}$.

Ese paso lo ha dado recientemente Ferrajoli ${ }^{60}$. Este autor comparte el ya aludido clásico punto de vista de que el juez tiene que vérselas con una forma particular de verdad histórica, puesto que no está a su alcance la observación directa de las conductas objeto de enjuiciamiento. Pero, señala, la investigación judicial «no consiste sólo en la recogida de datos y piezas de convicción, sino sobre todo en experimentar y producir nuevas fuentes de prueba»; de manera que «lo que el juez experimenta no son los hechos delictivos objeto del juicio, sino sus pruebas».

Ello, es decir, el intento de determinación de los hechos«probados» del pasado, a través del análisis de hechos «probatorios» del presente, confiere a la actividad las características de la inferencia inductiva.

Ahora bien, una inferencia inductiva peculiar en determinados aspectos, de los que algunos ya han quedado señalados. Y que cuenta además con otro relevante elemento diferencial y es que en la inferencia inductiva que realiza el juez cobra un valor esencial de signo positivo la falacia del argumentum ad ignorantiam, que se comete «cuando se sostiene que una proposición es verdadera simplemente sobre la base de que no se ha demostrado su falsedad (...) y que es falaz en todos los contextos excepto en uno: la corte

${ }^{59}$ M. Taruffo, «II giudice e lo storico: considerazioni metodologiche», en Rivista di Diritto Processuale, 1967, p. 445.

${ }^{60}$ En op. cit., pp. 25-26. 
de justicia» ${ }^{61}$. Es el principio de presunción de inocencia, al que ya aludió Calamandrei, al caracterizar al in dubio pro reo como instrumento preclusivo de la perplejidad del juez ${ }^{62}$, que juega ahora un papel central en la epistemología judicial, en la que no se limita a operar como regla de juicio, sino como verdadero eje del sistema.

\section{El detective}

La búsqueda de puntos de referencia metodológicos que puedan ser analógicamente explicativos de la naturaleza del trabajo del juez en materia de hechos, no se ha detenido en su asimilación al historiador.

Como es bien sabido, la investigación judicial parte de la constatación empírica de que se ha producido un determinado resultado. Un resultado anómalo, es decir, que rompe la normalidad. Desde esa evidencia primaria, llevada al juez habitualmente con un conjunto de otros datos, éste tratará de reconstruir el caso en la totalidad de sus elementos integrantes.

Este modo de proceder a partir de indicios $^{63}$, guarda relación con el modelo de la semiótica médica (donde el «indicio» es el «síntoma»), pero presenta también una cierta homología con el «razonar hacia atrás» de Sherlock Holmes.

Por eso, no tiene nada de extraño que filósofos y semiólogos se hayan ocupado del método de investigación criminal del personaje de Doyle con profundo interés ${ }^{64}$; creyendo haber encontrado en él una expresión del pensamiento de Ch. S. Peirce acerca de la hipótesis o abducción ${ }^{65}$.

Más recientemente Fassone ${ }^{66}$, siguiendo las observaciones de

${ }^{61}$ Cfr. I. M. Copi, op. cit., p. 65.

${ }^{62}$ En op. cit., p. 116.

${ }^{63}$ Indicio: «Cualquier cosa que indica la posibilidad de que haya existido, exista, haya ocurrido o vaya a ocurrir cierta cosa» (M. Moliner, Diccionario de uso del español. Gredos, Madrid, 1977).

${ }^{64}$ Il segno dei tre. Holmes, Dupin, Peirce. U. Eco y T. A. Sebeok (eds.), Bompiani, Milán, 1983, (hay traducción castellana de E. Busquets, Lumen, Barcelona, 1989), es un buen ejemplo.

Puede verse asimismo T. A. Sebeok y J. Umiker-Sebeok, Sherlock Holmes y Charles S. Peirce. El método de investigación. Trad. L. Güell, revisión de J. M. Pérez Tornero, Ediciones Paidos, Barcelona, 1987. (Este libro contiene en realidad lo que es el trabajo inicial de los reunidos en el anterior).

${ }^{65}$ Cfr. la voz «Abducción», en J. Ferrater Mora, op. cit., I, pp. 12-14.

${ }^{66}$ En op. cit. 
$E{ }^{67}$ sobre el particular, ha llevado directamente el punto de vista de Peirce al terreno de la reflexión sobre la prueba judicial.

En este planteamiento, el juez opera en su averiguación a partir del conocimiento del resultado y de una regla que actúan como premisas.

Ahora bien, tal regla no es equivalente a la ley general del razonamiento deductivo. Ésta se halla bien determinada y contiene en sí misma toda la información relevante; así, operar la subsunción del caso concreto es una simple aplicación, «una mera explicitación del contenido semántico de las premisas ${ }^{68}$ que, si se hace con el necesario rigor formal, garantiza la validez del resultado. Pero no produce aumento de saber empírico, es decir, no permite ir hacia adelante en el conocimiento, descubrir algo nuevo.

La abducción se caracteriza, en cambio, porque ella «mira a encontrar, junto al caso, también la regla» ${ }^{69}$. Ésta puede ser de más o menos fácil localización, pero nunca susceptible de simple aplicación con la garantía del resultado que cabe esperar en el caso de la deducción. Aquí el valor de verdad no está plenamente garantizado por la validez de las premisas, por eso existe un riesgo.

En resumen, en el razonamiento deductivo, como se sabe, se dispone de una premisa mayor, que es una regla a cuya naturaleza ya se ha aludido; y de una premisa menor, a partir de las cuales se obtiene una conclusión en la forma también expuesta.

En la abducción, lo primero que se conoce es la conclusión (Fulano ha sido hallado con un cuchillo clavado en el corazón), que es justamente el punto de arranque del razonamiento. Se tiene o se puede llegar, además, al conocimiento de ciertas reglas (máximas de experiencia) -sobre cuyas particularidades se hablará más adelante- que pueden hallarse más o menos codificadas, ser más o menos precisas, más o menos experimentadas, de mayor o menor nivel de generalidad. Pero de su aplicación, una vez identificadas, no se deriva una conclusión necesariamente válida, sino sólo probable.

Porque, en suma, como escribió Peirce, mientras «la deducción prueba que algo tiene que ser (...), la abducción sugiere meramente que algo puede serlo.$^{70}$ En nuestro caso,

${ }^{67}$ U. Eco, «Corna, zoccoli, scarpe. Alcune ipotesi su tre tipi di abduzione», en E. Eco y T. A. Sebeok (eds.), cit., pp. 237 y ss. cit., p. 152.

${ }^{68}$ M. A. Bonfantini y G. Proni, «To guess or not to guess?», en U. Eco y T. A. Sebeok (eds.),

${ }^{69}$ U. Eco, en op. cit., p. 244.

${ }^{70} \mathrm{Ch}$. S. Peirce, El hombre un signo. (El pragmatismo de Peirce). Traducción, introducción y notas de J. Vericat, Editorial Crítica, Barcelona, 1988, p. 136. 
una relación histórica, 
puesto que está referida a un momento pasado, y es la que se trata de establecer, entre un hecho y el acto causal.

Buscando precisar la diferencia entre la inducción y la abducción, el propio Peirce añadía que una y otra, naturalmente «conducen a aceptar una hipótesis en cuanto los hechos observados aparecen como consecuencias necesarias o probables de tales hipótesis», pero «la abducción toma su punto de partida de los hechos, sin tener, al principio, a la vista alguna particular teoría, aunque se encuentre motivada por la sensación de que se requiere una teoría para explicar hechos sorprendentes. La inducción parte de una hipótesis que parece sugestiva sin tener al inicio algún hecho en particular a la vista, aunque se tenga la sensación de la necesidad de hechos para sostener una teoría. La abducción busca una teoría. La inducción busca hechos. En la abducción la consideración de los hechos sugiere la hipótesis. En la inducción el estudio de la hipótesis sugiere los experimentos que hacen la luz sobre los hechos auténticos a los que la hipótesis se refiere» ${ }^{71}$.

De esta cita de Peirce puede extraerse una conclusión elemental, que en ningún caso sería polémica: cualquiera que fuera la relación que llegue a establecerse entre inducción y abducción, ambas serían siempre formas de inferencia ajenas al modelo deductivo, es decir, sintéticas, cuyo resultado es innovador con respecto al contenido de las premisas y, por eso, siempre arriesgado.

Por otra parte, el drástico criterio de demarcación de que Peirce hace uso para distinguir entre ambos modelos, en función del punto de partida (hipótesis/ hecho) y del objetivo (hechos/ teoría), ha sido seriamente cuestionado ${ }^{72}$.

En fin, y para lo que aquí interesa, importa señalar que en el caso del juez del enjuiciamiento, es cierto que su inferencia lleva de un caso particular a un caso particular, de un hecho a otro hecho. Pero, en el punto de partida, existe ya una hipótesis (la hipótesis acusatoria) que avanza una propuesta de interpretación

${ }^{71}$ Ch. S. Peirce, cit. por T. A. Sebeok y J. Umiker-Sebeok, «"Voi conoscete il mio metodo": un confronto fra Charles S. Peirce e Sherlock Holmes», en U. Eco y T. A. Sebeok, Il segno dei tre, cit., p. 44.

${ }^{72}$ Así, por ejemplo, N. R. Hanson: «Muchos rasgos de la resolución de problemas reales por parte de la gente ordinaria y de los científicos ordinarios, exige la comprensión de los criterios en virtud de los cuales pueden distinguirse las buenas razones de las malas razones. Mucho antes de que un investigador haya acabado su investigación, haya solucionado su problema y haya escrito finalmente su informe de investigación, debe haber habido muchas ocasiones en las que se ha visto forzado a usar su cabeza, a invocar su razón, y a decidir entre las especulaciones que parecían potencialmente fructíferas y las que no lo parecían» (en op. cit., p. 52). 
del hecho motivador de la apertura del proceso. Y, desde luego, la indagación judicial no lleva a la construcción de teorías.

De este modo, cabe concluir con Besso Marcheis que «el razonamiento abductivo puede proponerse como un modelo útil de descripción de momentos diversos y anteriores respecto al de la valoración de las pruebas y resulta, así, de utilidad bastante limitada a los fines de nuestro discurso» ${ }^{73}$. Por eso, y como enseguida se expone, siguiendo a Ferrajoli, parece que se puede dar cuenta de la estructura del operar judicial acudiendo al modelo inductivo.

\section{CONVICCIÓN LIBRE DEL JUEZ: DE INSPIRACIÓN A INDUCCIÓN}

\section{Intime conviction}

Desde que a partir del siglo XIII «la aritmética de las pruebas sustituyó al razonamiento ${ }^{74}$, el sistema de la prueba legal aparece unido a la experiencia del proceso inquisitivo.

Como se sabe, la teoría de la prueba legal guarda íntima relación con la figura de un juez estrechamente vinculado al poder que hoy diríamos ejecutivo, y a una concepción fuertemente autoritaria del proceso, concebido a su vez como instrumento capaz de procurar una verdad no probable, sino real sobre los hechos, apta para justificar incluso el recurso al tormento ${ }^{75}$. Por eso, sin perjuicio de cualquier otro tipo de consideraciones que al respecto pudieran hacerse, conviene no perder de vista la idea apuntada por Giuliani de que «el problema de la tortura fue un problema de lógica ${ }^{76}$. Es decir, una cuestión instrumental, de manera que si el proceso estaba preordenado a la obtención de una verdad absoluta, ésta, como fin, podría justificar el empleo de cualquier medio.

${ }^{73} \mathrm{C}$. Besso Marcheis, «Probabilità e prova: considerazioni sulla struttura del giudizio di fatto», en Rivista Trimestrale di Diritto e Procedura Civile, n. 4, 1991, p. 1.138.

${ }^{74}$ A. Giuliani, Il concetto di prova. Contributo alla logica giuridica. Giuffrè, Milán, 1971, p. 184.

${ }^{75} \mathrm{~F}$. Cordero sitúa en el sustrato cultural del modelo inquisitivo la convicción de que «el Mal existe, anida por todas partes con temibles quintas columnas, y, puesto que el inquisidor lo combate, todo proceso es una diablomaquia». (De "Stilus curiae (analisi della sentenza penale)», en La sentenza in Europa. Metodo, tecnica e stile (Atti del Convegno internazionale per l'inaugurazione della nuova sede della Facoltà, Ferrara, 10-12 ottobre 1985), Cedam, Padua, 1988, p. 297.

${ }^{76}$ En op. cit., p. 185. 
En tal perspectiva, el criterio de la prueba tasada, al establecer «ciertas bases de prueba que la experiencia de mucho tiempo ha acreditado como orígenes los más seguros de certeza $\gg{ }^{77}$ respondía, formalmente al propósito de limitar el arbitrio del juez, que, dotado de una libertad extrema en la indagación, quedaría, no obstante, constreñido en sus apreciaciones a la predeterminación normativa del valor de las adquisiciones probatorias ${ }^{78}$.

No obstante este punto de partida, lo cierto es que el modelo, como no podía ser menos, dio lugar a unas prácticas ${ }^{79}$ que condujeron «a la quiebra del sistema, tanto desde el punto de vista gnoseológico como moral ${ }^{80}$.

Bien reveladoras al respecto son las palabras de Voltaire, en su comentario al libro de Beccaria, al denunciar la admisión de «medias pruebas que no son en realidad más que dudas, pues es sabido que no existen medias verdades; pero en Toulouse se admiten las cuartas y octavas partes de prueba. Por ejemplo, un he oído decir, puede ser considerado como un cuarto de prueba, y otro he oído decir un poco más vago, como una octava parte;

${ }^{77}$ C. J. A. Mittermaier, Tratado de la prueba en materia criminal, sin ref. de trad. Imprenta de la Revista de Legislación, Madrid, 1877, p. 30.

${ }^{78}$ La pretensión, implícita en el sistema de la prueba legal, de sujetar al juez en su valoración a reglas de carácter supuestamente universal, dotadas de un, también supuesto, valor probatorio pleno, daba al modelo de razonamiento empleado, como ha señalado Ferrajoli, una falaz estructura deductiva y por ello, una «aparente racionalidad», no obstante lo cual el esquema lógico subyacente es el mismo que «está en la base de las pruebas irracionales de tipo mágico y arcaico: la ordalía, el duelo judicial, el juramento, la adivinación». (Op. cit., pp. 113-114).

No veo contradicción entre este punto de vista y el de Tomás y Valiente al aceptar que «tal vez» la tortura pudo significar «algo más racional que las ordalías» puesto que «fue un elemento probatorio jurídicamente regulado dentro de un proceso (de un proceso predominante o enteramente inquisitivo), y por tanto superador del anterior par de fuerzas ofensa-venganza». (En La tortura en España, cit., p. 214).

En efecto, mientras la reflexión de Ferrajoli alude a una racionalidad epistemológica, la de Tomás y Valiente lo hace a una de tipo más bien empírico. Como cuando G. Amato, a propósito del mismo asunto, ve en la tortura medieval un tormento con garantías, que se pierden en la tortura renacentista. (Individuo e autorità nella disciplina della libertà personale. Giuffrè, Milán, 1970, pp. 96-97).

${ }^{79}$ Sobre las prácticas del sistema ilustran muy bien: P. Verri, Observaciones sobre la tortura. Traducción, prólogo y notas de M. De Rivacoba, Ediciones Depalma, Buenos Aires, 1977; y A. Manzoni, Historia de la columna infame. (Con nota de L. Sciascia), trad. de E. Gallego, Alianza Editorial, Madrid, 1987. Acerca de la experiencia española al respecto, cfr. F. Tomás y Valiente, $E l$ derecho penal de la monarquía absoluta (siglos XVI-XVII-XVIII), Tecnos. Madrid, 1969, pp. 171 y ss.; y La tortura en España, Ariel, Barcelona, 1973.

${ }^{80}$ M. Nobili, op. cit., p. 112. 
de modo que ocho rumores que no son en realidad más que el eco de un rumor mal fundado, pueden componer una prueba completa...» ${ }^{81}$.

Lo cierto es que la prueba legal experimentó las mismas vicisitudes que el proceso inquisitivo en su conjunto, a expensas sobre todo de la oposición que al mismo se hace desde los presupuestos político-filosóficos de la ilustración ${ }^{82}$.

Entre éstos se cuenta la renovada confianza en la razón, que lleva a una revalorización del «sentido común» ${ }^{83}$, y a que se ponga la vista en los jurados populares, opción a la que no es ajena una cierta influencia de la experiencia procesal inglesa. Esta tendencia, que tiene clara expresión en obras como la de Filangieri ${ }^{84} \mathrm{y} \mathrm{Bentham}^{85}$, entre otros, cristaliza de forma paradigmática en la obra de la Asamblea Constituyente francesa.

La finalidad y el alcance de este trabajo obligan a pasar por alto las vicisitudes del principio de la intime conviction; particularmente aquéllas que, desplazándolo de sus raíces originales, dan razón de su definitiva inserción en el modo de operar de las magistraturas profesionales. En su virtud, el juzgador en el marco del juego del principio de legalidad aparecerá facultado para valorar libremente las pruebas practicadas, según su conciencia.

A partir de ese momento, el principio, tanto en alguna teorización doctrinal como, sobre todo, en la práctica, apareció extraordinariamente teñido de subjetivismo, cual si el ejercicio de esa libertad de apreciación de datos probatorios en un contexto

${ }^{81}$ Voltaire, «Comentario al libro de los delitos y de las penas», en apéndice a C. Beccaria, De los delitos y de las penas. Trad. J. A. De las Casas, Alianza Editorial, Madrid, 1968, p. 158.

${ }^{82}$ Aunque la obligación de motivar las resoluciones judiciales fue una exigencia estimulada y favorecida por la cultura jurídica de la ilustración, ésta, sin embargo, no se manifiesta de manera unívoca en la materia. Así, la consideración del juez como bouche de la loi, no deja prácticamente espacio para la motivación en la cuestión de hecho, puesto que conceptualmente elimina cualquier libertad del juzgador. Sobre este asunto, puede consultarse con provecho M. Taruffo, «L'obbligo di motivazione della sentenza civile tra diritto comune e illuminismo», en Rivista di Diritto Processuale, 1974, pp. 18 y ss.

${ }^{83}$ Cfr. al respecto M. Nobili, op. cit., pp.131 y ss.

${ }^{84}$ C. Filangieri, Ciencia de la legislación. Trad. de J. Ribera, Imprenta de D. Fermón Villalpando, Madrid, 1821, vol. III, pp. 154 y ss. No obstante, hay que señalar que Filangieri se muestra partidario de «combinar la certeza moral del juez con la norma prescrita por el legislador, esto es, con el criterio legal» (p. 155).

${ }^{85}$ «¿Qué es una regla falsa en materia de procedimiento? Es una regla que tiende a poner en contradicción la decisión del juez y la ley; que constriñe al juez a pronunciarse en contra de su íntima persuasión» (J. Bentham, Tratado de las pruebas judiciales. Trad. de M. Ossorio Florit, Ejea, Buenos Aires, 1959, vol. I, p. 12). 
legal fuera, más que actividad racional, una especie de momento místico ${ }^{86} \mathrm{y}$, en cuanto tal, incontrolable. Así, entre nosotros, un comentarista tan autorizado como Aguilera de Paz interpretará el art. 741 de la Ley de Enjuiciamiento Criminal como la atribución al juez de un cometido que debe desempeñar «respondiendo a los dictados de la conciencia según las inspiraciones de su propio juicio acerca de la verdad de los hechos rectamente apreciados» ${ }^{87}$.

El riesgo de tal degradación del principio no pasó desapercibido a Carrara, quien ya advirtió que «respecto al juicio acerca del hecho, el juez no tiene verdadero arbitrio, ni siquiera cuando se acepta su convicción íntima, pues siempre debe convencerse según la razón y según el proceso ${ }^{88}$.

Que el juez no puede ser libre de la prueba ${ }^{89}$, es algo que, así formulado, no discutiría ni el más entusiasta de los defensores del principio que nos ocupa entendido $s u b$ specie del subjetivismo más extremo. Sin embargo, lo cierto es que, al postular un tipo de relación del juez con el resultado de la actividad probatoria, del género del que subyace al punto de vista doctrinal aludido y que cabe rastrear también en no pocas manifestaciones jurisprudenciales $^{90}$, se está implícitamente apostando por una libertad para el juzgador que no conoce ni siquiera aquel límite.

${ }^{86}$ Cordero, con palabras que ya son, por su expresividad, un obligado lugar común en la materia, se referirá críticamente «a la imagen del libre convencimiento como de una voraz potencia superlógica». Para afirmar su oposición a que «la libre convicción sea una suerte de potencia dionisíaca de la que no se pueda hablar sino en los términos alusivos con que la bacante hablaba del dios; que el intelecto no sea omnipotente no es un buen motivo para renunciar a usarlo donde podría ahora iluminarnos» (F. Cordero, Ideologie del processo penale. Giuffrè, Milán, 1966, pp. 229-230).

${ }^{87}$ En op. cit., vol. V, p. 560. «El legislador ha dejado en absoluto a la conciencia del juzgador la apreciación de las pruebas» (p. 558).

${ }^{88}$ F. Carrara, Programa de derecho criminal. Trad. de J. J. Ortega Torres y J. Guerrero, Editorial Temis, Bogotá, 1957, vol. II, p. 356.

${ }^{89}$ Tomo la expresión de G. Bettiol, Istituzioni di diritto e procedura penale. Cedam, Padua 1966, p. 203. (Hay traducción castellana, de Gutiérrez-Alviz y Conradi, Reus, Madrid).

La misma idea puede verse expresada en la sentencia de la Sala Segunda del Tribunal Supremo (Huet García, 7 de junio de 1991): «valoración de la prueba en conciencia o íntima convicción del juzgador quiere decir, sin duda, libertad de apreciación de la prueba, pero no prescindir de la misma ni de su análisis...». Aunque no podría afirmarse que la Sala Segunda sea consecuente en la exigencia del contenido de la última afirmación, puesto que es, como regla, francamente tolerante con la omisión del análisis de la prueba en las sentencias de que conoce.

${ }^{90}$ Críticamente, sobre la incidencia de esta actitud en la jurisprudencia de nuestro país de los años 30 a 50 de este siglo, cfr. J. M. Martínez Pereda, «El 
En efecto, no basta la afirmación ritual de la vinculación del juez a las aportaciones probatorias. La propia experiencia histórica en la materia no podía ser más elocuente acerca de los límites de la capacidad efectivamente ordenadora de la norma, una vez acreditadas las vicisitudes del propio sistema de la prueba legal.

Esta evidencia, y puesto que la actividad valorativa del juez no puede darse sin un soporte de conocimiento previo racionalmente obtenido y que -en la moderna disciplina constitucional del proceso- ha de ser, además, motivado erga omnes, hace que, como lúcidamente apuntó Nobili, el nudo de la cuestión relativa a «la validez de las nuevas reglas» tenga que desplazarse del campo «de la imperatividad de la norma jurídica» al de la «fundamentación y eficacia científica»" ${ }^{91}$.

\section{La inferencia inductiva del juez}

La representación ideal del modo de razonar del juez como un silogismo, que tiene en la conocidísima formulación de Beccaria ${ }^{92}$, su expresión más acabada, aunque sigue formando parte del bagaje cultural de no pocos profesionales del derecho ${ }^{93}$, ha sido eficazmente cuestionada en su capacidad descriptiva ${ }^{94}$.

convencimiento judicial en el proceso penal español», Revista de derecho judicial, n, 13, 1963, pp. $42-43$.

${ }^{91}$ En op. cit., p. 196.

${ }^{92}$ «En todo delito debe hacerse por el juez un silogismo perfecto. Podrase como mayor la ley general, por menor la acción conforme o no con la ley, de que se inferirá por consecuencia la libertad o la pena» (C. Beccaria, op. cit., p. 31).

Del grado de aceptación de este punto de vista da cuenta suaceptación por procesalistas de tanto relieve corno Carnelutti (cfr. La prueba civil. Trad. de Alcalá-Zamora y Castillo, Ediciones Depalma, Buenos Aires, 1982, pp. 62-63).

${ }_{93}$ Para muestra un botón, en una sentencia reciente de la Sala Segunda del Tribunal Supremo (Moner, 10 de enero de 1992) puede leerse: «...dentro del silogismo que entraña la sentencia...».

${ }^{94}$ En esta línea vale la pena dejar constancia aquí del punto de vista de Taruffo: «Hablar de función ideológica de la teoría silogística del juicio significa poner en evidencia que ésta tiende a acreditar una determinada imagen del juez, más que del juicio, destinada no tanto a delinear una realidad concreta, como a indicar cuál debería ser tal realidad. En efecto, la doctrina del silogismo judicial, más que describir el juicio, construye un modelo abstracto e ideal de juicio: se plantea una situación en la que la norma es un dato preexistente, en un ordenamiento positivo completo y sistematizado, cuya interpretación en vista de la aplicación al caso concreto consiste en una actividad esencialmente cognoscitiva de carácter sistemático. Se presupone además que una actividad de este género es en todo caso necesaria y suficiente, sin que deban intervenir operaciones y apreciaciones no reducibles dentro del módulo del polisilogismo» (En La motivazione, cit., pp. 163-164). 
Sin embargo, creo que en ningún caso se había hecho con el rigor con que Ferrajoli ha llevado a término la, seguramente, más acabada tarea de crítica y propuesta de un modelo alternativo de comprensión del modo de operar jurisdiccional.

A su juicio ${ }^{95}$, ninguna de las dos operaciones mediante las que se obtiene la verdad procesal responde al esquema del silogismo: ni la inducción representada por la prueba de los hechos, ni la deducción en que consiste la calificación jurídica de los mismos tienen la forma de las proposiciones normativas, sino de proposiciones asertivas, es decir, relativas a la existencia o inexistencia de determinados hechos y preceptos legales. En uno y otro caso se tratará de enunciados de los que puede predicarse verdad o falsedad.

Frente a lo sostenido por Beccaria, Ferrajoli ve en el modus operandi del juez no una inferencia, sino tres: una inferencia inductiva, que tiene como premisas el resultado de la actividad probatoria y permite afirmar, por ejemplo, que Fulano ha causado la muerte de Mengano; una inferencia deductiva, que tiene como premisa la anterior afirmación de hecho y un precepto, en este caso del C. Penal, y permite afirmar, como conclusión, que Fulano ha cometido un delito de homicidio; y un silogismo práctico, que integra la parte dispositiva, cuyas premisas son normativas (Fulano ha cometido un homicidio; al homicidio corresponde tal pena) y cuya conclusión es también una norma para el caso concreto: Fulano debe ser condenado a tal pena.

Así resulta que el lugar del silogismo de Beccaria ha sido ocupado por dos silogismos de carácter teórico y un silogismo práctico o deóntico.

Acoger metodológicamente el carácter de inferencia inductiva de la averiguación de los hechos, supone a la vez asumir algo que, no obstante su aparente obviedad, tiene una relevancia que no debe desconocerse. Me refiero al dato de que con ello se sitúa reflexivamente el quehacer cognoscitivo del juez respecto de los hechos en el ámbito de las explicaciones probabilísticas, que son las que permiten afirmar algo, pero solo, y si la derivación es correcta, «con un alto grado de probabilidad, y quizá con "certeza práctica"»"

Entre nosotros se cuestiona ya la concepción silogística, por ejemplo, en M. Fenech, Derecho procesal penal. Labor, Barcelona, 2. ${ }^{a}$ ed. 1952, vol. 22, p. 237.

Más recientemente, sobre los límites de la categoría referida a la decisión judicial, lo ha hecho M. Atienza, op. cit., pp. 39 y ss.

${ }^{95}$ Lo que sigue se funda en L. Ferrajoli, op. cit., pp. 38 y ss. y 107 y ss.

${ }^{96}$ C. G. Hempel, Filosofía de la ciencia natural. Trad. de A. Deaño, Alianza Editorial, Madrid, 1973, p. 93. 
De ello se sigue una consecuencia que no debe perderse de vista: probabilidad implica un margen de incertidumbre y de libertad de elección entre opciones; cuando ésta conduce a decisiones que afectan a bienes personales extraordinariamente sensibles, la incertidumbre implica a su vez una forma de poder. Un poder que, como inevitablemente discrecional en algún grado, nunca será del todo controlable ${ }^{97}$.

Así las cosas, y para que esos márgenes de incertidumbre puedan verse reducidos tanto como sea posible, es fundamental que la inferencia judicial tenga siempre un referente empírico bien identificable ${ }^{98}$, que haga posible afirmar con rigor si las proposiciones relativas a él son verdaderas o falsas, evitando que bajo la apariencia de enunciados descriptivos se formulen sólo juicios de valor ${ }^{99}$.

La inferencia judicial tiene su punto de partida en un acaecimiento humano que rompe de algún modo la normalidad, de forma que interesa al ordenamiento penal. Ello da lugar a la formulación de una hipótesis acusatoria, que como cualquier hipótesis es un «enunciado sometido a contrastación» ${ }^{100}$.

Contrastar una hipótesis es, como se sabe, poner a prueba su valor explicativo, en este supuesto, del caso a examen. Tratándose

${ }^{97}$ Hay en nuestra cultura procesal una marcada inclinación a atribuir a los juicios de hecho naturaleza deductiva (cfr. de la Sala Segunda sentencias de: Puerta Luis, 27 de mayo de 1991; Soto Nieto, 17 de junio de 1991; Huerta Álvarez de Lara, 29 de junio de 1991; Montero Fernández-Cid, 12 de julio de 1991; Ruiz Vadillo, 4 de septiembre de 1991); en lo que no parece arriesgado ver una resistencia implícita a aceptar que el conocimiento del juez en la materia no es el conocimiento en sentido fuerte que tradicionalmente se ha asimilado a la lógica deductiva. A ello responde la que Taruffo ha llamado «"juridización” del juicio de hecho, que así resulta en buena medida reabsorbido en el ordenamiento como sistema completo y cerrado de criterios de decisión» (en La motivazione, cit., p. 164, nota).

${ }^{98}$ Es evidente que esta exigencia tiene que hallarse previamente satisfecha en la ley, mediante la efectividad del principio de «estricta legalidad». Éste (frente al de «mera legalidad», que va dirigido al juez y le impone la observancia de lo dispuesto en la ley) «se dirige al legislador, al que prescribe la taxatividad y determinación empírica de las formulaciones legales». Porque, «sólo cuando están dotadas de precisas referencias empíricas y fácticas, las definiciones legales de las hipótesis de desviación son adecuadas para determinar de manera tendencialmente exclusiva y exhaustiva su campo de aplicación» (L. Ferrajoli, op. cit., p. 7).

${ }^{99}$ Naturalmente, no se pretende expulsar los juicios de valor de una actividad como la judicial, en la que el momento valorativo ocupa un lugar fundamental. Se postula sin embargo un esfuerzo, una tensión -como actitud metodológica- orientada a que el juez opere con ellos de forma consciente y en el momento en que ha de hacerlo.

${ }^{100}$ C. G. Hempel, op. cit., p. 38. 
del enjuiciamiento, ello se hace mediante el desarrollo de la actividad probatoria ${ }^{101}$.

Para que la hipótesis acusatoria pueda considerarse válida, se precisa una pluralidad de confirmaciones. La fecundidad de una hipótesis requiere que la misma sea confirmada por más de un hecho. (El único hecho de haber estado Fulano en el lugar del crimen no lo acredita, sin más, como autor del mismo).

Es preciso asimismo que la hipótesis sea resistente a las contrapruebas aportadas por la defensa. Una sola contraprueba eficaz basta para desvirtuar una hipótesis: si la coartada es verdadera la hipótesis es falsa.

Tienen que resultar también desvirtuadas todas las hipótesis alternativas.

En todo este proceso, deben de tenerse en cuenta algunas indicaciones. Así, cuanto mayor es la distancia y por tanto mayor es el número de inferencias que han sido necesarias para derivar de los hechos probatorios el thema probandi, menor es el grado de probabilidad de la inducción probatoria.

Prueban más las pruebas que son más ricas en contenido empírico. Por eso si concurren varias hipótesis alternativas, se ha de optar por la más simple ${ }^{102}$.

Cuando al final de ese proceso de conocimiento el juez aventura unos hechos como probados, habrá formulado a su vez una hipótesis acerca de la forma en que los mismos tuvieron lugar. Una hipótesis probabilística, como consecuencia de que en la inferencia inductiva la conclusión va más allá de las premisas, aporta algo que no está contenido necesariamente en éstas y supone, en esa medida, un cierto salto hacia adelante.

Esto es lo que da un sentido también epistemológico ${ }^{103}$ a la

${ }^{101}$ Ferrajoli propone «llamar prueba al hecho probatorio experimentado en el presente del que se infiere el delito u otro hecho del pasado, e indicio al hecho probado del pasado del que se infiere el delito u otro hecho del pasado que tenga a su vez el valor de un indicio».

El modelo, ilustra Ferrajoli, funciona así: Fulano testifica que ha visto a Mengano salir de casa de Perengano con un cuchillo ensangrentado en la mano, poco antes de que éste fuese hallado muerto de una cuchillada. Pues bien, tal afirmación es prueba, más o menos probable, según la sinceridad de Fulano, del hecho de que él ha visto a Mengano... Este segundo hecho es, en cambio, sólo un indicio, a su vez más o menos probable, según el crédito que se dé a la vista de Fulano, de que Mengano ha salido realmente de la casa de Perengano en las circunstancias que se ha dicho. Este tercer hecho es, a su vez, un indicio, más o menos probable según la plausibilidad de los nexos causales establecidos por nosotros, de que Mengano ha matado a Perengano. (Op. cit., pp. 108-109).

${ }^{102}$ Cfr. C. G. Hempel, op. cit., pp. 67 y ss.

103 «Las garantías penales y procesales, además de garantías de libertad, son 
existencia de las garantías procesales, que configuran un marco normativo, regido por el principio de presunción de inocencia, en el que la inducción judicial ha de desenvolverse. Pero que en ningún caso altera la naturaleza probable del conocimiento adquirido por ese medio.

Ferrajoli se muestra partidario de acudir al esquema nomológico-deductivo ${ }^{104}$, como medio de acreditar, de evaluar, la consistencia de la inferencia inductiva del juez. Esto permitiría alcanzar una justificación relativa, al permitir identificar los criterios de decisión.

Como se ha visto, la inferencia inductiva permite ir del thema probandi descrito en la hipótesis acusatoria a los hechos probatorios que son su explicación. Ahora bien, una vez realizada aquélla, puede dársele la vuelta, puede invertirse su curso, tratándola como si fuera una inferencia deductiva.

En ésta los hechos probatorios constituirán una primera premisa que, puesta en relación con otra: alguna(s) ley(es) o generalización(es) empírica(s) comúnmente aceptada(s) -máximas de experiencia en terminología procesal-, permitirá tener como probado el hecho de que se trata. $\mathrm{O}$ pondrá de manifiesto que no se procedió correctamente en la inferencia $\operatorname{previa}^{105}$.

Esta ulterior manera de operar es evidente que no convierte lo obtenido a través de ella en conocimiento deductivo, puesto que no altera el proceso cognoscitivo como tal ${ }^{106}$. No cambia por

también garantías de verdad; (porque) "saber" y "poder concurren de manera diversa en el juicio, según que las mismas sean más o menos realizables y satisfechas» (L. Ferrajoli, op. cit., p. 19).

${ }_{104}$ Precisa su propuesta en op. cit., pp. 120-123. Sobre el modelo de explicación nomológica-deductiva, cfr. C. G. Hempel, op. cit., pp. 79 y ss.; y J. Echevarría, op. cit., p. 55.

${ }^{105}$ Una aproximación intuitiva a la elaborada propuesta de Ferrajoli, puede verse en G. Walter, cuando exige del juez una forma de apreciación y de expresión de la apreciación de la prueba «que sea repetible mentalmente». (En Libre apreciación de la prueba. Investigación acerca del significado, las condiciones y los límites del libre convencimiento judicial. Trad. de T. Banzhaf, Temis, Bogotá, 1985, p. 359.

${ }^{106}$ Como escribe Letizia Gianformaggio, a diferencia de lo que sucede en el razonamiento deductivo, en el inductivo «la mera enunciación de la premisa, o eventualmente de las premisas, no es suficiente para probar de manera rigurosa alguna conclusión. Se sabe bien que una inferencia inductiva debe probarse, y la prueba viene dada por un elemento extraño al razonamiento». («Modelli di ragionamento giuridico. Modello deduttivo, modello induttivo, modello retorico», en U. Scarpelli (ed.), La teoria generale del diritto. Problemi e tendenze attuali. Siudi dedicati a Norberto Bobbio. Edizioni di Comunità, Milán, 1983, p. 144). Y es evidente que ese paradigma no se altera por la inversión nomológica-deductiva de un previo razonamiento inductivo. 
tanto la naturaleza probabilística del conocimiento adquirido, pero tiene indudables ventajas, desde el punto de vista del control de la calidad del curso argumental del juez: por un lado le obliga a ordenar el material probatorio ya contrastado, a verificar la forma en que lo ha sido, y a hacer explícitas las máximas de experiencia empleadas; y, por otro, permite también apreciar con más facilidad hasta qué punto uno y otras en su interacción explican y en qué medida, o no explican, en el caso concreto.

\section{El papel de las máximas de experiencia}

$\mathrm{Al}$ hablar de esta materia continúa siendo un punto de referencia necesario la noción elaborada por Stein, que concibió las máximas de experiencia como «definiciones o juicios hipotéticos de contenido general desligados de los hechos concretos que se juzgan en el proceso, procedentes de la experiencia, pero independientes de los casos particulares de cuya observación se han inducido y que, por encima de esos casos, pretenden tener validez para otros nuevos» ${ }^{107}$.

En una primera aproximación, la noción apunta a algo tan obvio como que resulta impensable que alguien -incluido el juez- pudiera prescindir, en el ejercicio de cualquier actividad de indagación o valoración, de los datos o el bagaje de conocimientos que proporciona la experiencia socialmente acumulada.

Sin embargo, el relieve adquirido por la noción en el momento y en la cultura procesal de que es buena expresión el trabajo de Stein, no se limita a esa perspectiva.

Como ha señalado Taruffo ${ }^{108}$, esa elaboración doctrinal consistente en «traducir en reglas lógicamente determinadas el criterio del id quod plerumque accidit», respondió de manera inmediata a la necesidad de salir al paso de las tesis de la escuela libre del derecho. $\mathrm{Y}$, más en concreto, a la finalidad de hacer posible un control sobre el juicio de hecho por parte de la casación.

Por esa vía, una vez traducidos a reglas generales los criterios extraídos de la experiencia, el juicio de hecho recibía cierta impronta normativa y el tratamiento lógico de una inferencia deductiva, de la que la máxima de experiencia venía a constituir la premisa mayor.

p. 27.

${ }^{107}$ F. Stein, El conocimiento privado del juez. Trad. de A. De la Oliva, Temis, Bogotá, 1988,

${ }^{108}$ M. Taruffo, Studi sulla rilevanza della prova. Cedam, Padua, 1970, pp. 197 y ss. 
Lo expresaba con claridad Rosemberg, al considerar el juicio de hecho como «una conclusión obtenida mediante subsunción de lo percibido en ciertos conceptos generales o máximas de experiencia como proposición mayor y formado, por tanto, mediante reglas lógicas»» ${ }^{109}$.

Se advierte fácilmente que esta forma de concebir la máxima de experiencia sigue estando profundamente instalada en la consideración jurisprudencial del juicio de hecho, como lo ponen de manifiesto las referencias concretas que se han hecho antes.

Y no puede tampoco pasar desapercibido que la misma, además de la función reconocida de propiciar el control lógico del juicio, tiene una clara dimensión ideológica: atribuir al conocimiento judicial del dato empírico una calidad de certeza (deductiva) que no tiene en absoluto. Y no la tiene porque la ley en que se traduce la máxima de experiencia no es una ley «de forma universal», sino el fruto de la constatación de cierta regularidad en la forma de producirse determinados fenómenos o comportamientos ${ }^{110}$.

La máxima de experiencia responde al esquema de la inducción generalizadora, de las generalizaciones empíricas, $\mathrm{y}$, en consecuencia, produce únicamente conocimiento probable. Esto no le priva de valor en la experiencia procesal, al contrario, permite atribuirle el que realmente puede corresponderle y, en esa misma medida, tal reconsideración de su significación se inscribe con toda autenticidad en el paradigma de búsqueda de la verdad de los hechos.

Por otra parte, resulta casi innecesario decir que no todas las máximas de experiencia estarán dotadas de la misma eficacia explicativa en el momento de dar el salto de un hecho probatorio a otro que pueda considerarse probado.

Así, mientras algunas máximas de experiencia -piénsese en las que rigen la pericia dactiloscópica- gozan de un alto grado de elaboración y reconocimiento; otras podrán ser el fruto de un

${ }^{109}$ En Tratado de derecho procesal civil. Ejea, Buenos Aires, 1955, vol. II, p. 210; cit. por H. Devis Echandía, Teoría general de la prueba judicial. Víctor P. de Zavalía Editor, Buenos Aires, vol. I, p. 175.

${ }^{110}$ «...la distinción entre leyes de forma universal y leyes de forma probabilística no se refiere a la fuerza del apoyo empírico de los dos tipos de enunciados, sino a su forma, que refleja el carácter lógico de la aserción que hacen. Una ley de forma universal es básicamente un enunciado en el sentido de que todos los casos en que se dan unas condiciones de tipo $F$ se dan también unas condiciones de tipo $G$; una ley de forma probabilística afirma, básicamente, que bajo ciertas condiciones, que constituyen la ejecución de un experimento aleatorio $R$, se producirá un cierto tipo de resultado en un porcentaje específico de casos» (C. G. Hempel, op. cit., p. 102). 
reducido número de datos empíricos ${ }^{111}$, e incluso tener necesidad de ser, a su vez, probadas $^{112}$.

Ahora bien, y como conclusión, con independencia de la calidad de la máxima de que se haga uso en cada caso, lo cierto es que, como escribiera Foschini, «percibido el hecho fuente de prueba, éste permanecería absolutamente carente de significado y mudo, a los fines de la prueba, si no estuviera referido a la experiencia y, más precisamente, subsumido en una máxima de experiencia, porque sólo de ese modo resulta posible obtener el convencimiento acerca de la verdad del hecho diverso que es objeto de prueba» ${ }^{113}$.

\section{LA MOTIVACIÓN DE LOS HECHOS EN SERIO}

El precepto contenido en el art. 120,3 de la Constitución, más que cerrar, realmente abre el problema de la motivación, porque, una vez atribuido a ésta de modo inequívoco el carácter de deber -constitucional- del juez, resulta inexcusable plantearse el problema de sus dimensiones, del alcance de la exigencia.

Como es bien sabido, esa norma de nuevo cuño, fue a proyectarse en un contexto caracterizado por la escasa cultura y la práctica todavía más pobre de la fundamentación de las resoluciones judiciales. En efecto, la sentencia penal estándar, el estilo de las resoluciones judiciales entre nosotros, estaba caracterizado por la declamación, por el hábito de la declaración apodíctica de ciertos hechos como «probados», siguiendo en la forma el torturado y torturador modelo de la francesa phrase unique, redactada en jerga impenetrable, siempre bien aderezada de gerundios ${ }^{114}$. Tales

${ }^{111}$ M. Nobili se muestra partidario de distinguir entre máximas de experiencia y lo que describe como «criterios sólo tendenciales del comportamiento humano» («Nuove polemiche sulle cosidette "massime d'esperienza" ", en Rivista Italiana di Diritto e Procedura Penale, 1969, p. 184).

${ }^{112}$ Sobre este último aspecto, cfr. H. Devis Echandía, op. y loc. cit., pp. 171 y ss.

${ }^{113}$ G. Foschini, Sistema del diritto processuale penale (I). Giuffrè, Milán, 1965, pp. 414-415.

Es por lo que Amodio insiste en la necesidad de «hacer explícito el canon de argumentación utilizado para llegar a la afirmación de haberse producido el hecho imputado». Así, el modelo normativo de la motivación, se desarrolla según la siguiente secuencia: «hecho probatorio -máxima de experiencia - hecho probado», (En op. cit., pp. 208-209).

${ }^{114}$ Cfr. Joaquín Bayo Delgado, «De gerundios jurídicos», en Boletín Informativo Jueces para la Democracia, n. 7, octubre 1991, p. 6; interesante apunte crítico sobre las particularidades del estilo de redacción que caracteriza a ese modelo. 
hechos, seguidamente, se declaraban, con fórmula sacramental y sin ninguna pretensión explicativa, constitutivos de una determinada infracción penal, haciéndolo como si de una derivación puramente mecánica se tratase.

Esta tradición sigue harto viva todavía en la práctica de muchos juzgados y tribunales, aunque a partir de momentos relativamente próximos, ha comenzado a experimentar cambios cuyo relieve no sería justo desconocer.

Así, puede decirse, va abriéndose camino entre nosotros una cierta nueva cultura de la motivación en la que, sin embargo, pesa más el lastre del viejo decisionismo inmotivado que el impulso emanado del imperativo del texto fundamental; sobre todo, en lo que hace referencia a la quaestio facti.

Es cierto que la relevancia de la motivación en la materia goza de autorizado reconocimiento jurisprudencial del más alto rango ${ }^{115}$. Pero también lo es que, no obstante lo categórico de muchas de las aserciones, las propias resoluciones en las que ese criterio se expresa, fácilmente pasan luego, sin solución de continuidad, a dar por bueno lo que no son sino verdaderas ausencias de motivación.

Tal es, por ejemplo, el caso de la llamada motivación implícita, o motivación «no dicha ${ }^{116}$, que cuenta con una franca aceptación en nuestra jurisprudencia ${ }^{117}$. Sobre todo

${ }^{115}$ Expresiva al respecto resulta la sentencia 55 / 1987 del Tribunal Constitucional (Díez Picazo), que en un tema de imprudencia señalaba la necesidad de establecer «motivadamente de qué manera la infracción del deber de diligencia se conecta con el resultado». Y también la de la Sala Segunda del Tribunal Supremo, de 20 de febrero de 1990, en que, tras de afirmar que en el campo penal «la relación de hechos probados es la piedra angular» se hacía hincapié en que «si no se dan razones sobre el valor que el juzgador concede a la prueba practicada y se limita la sentencia, como ha sido norma hasta tiempos recientes, a expresar la calificación jurídica de los hechos que se habían declarado probados mediante un razonamiento que se mantenía secreto en la conciencia de sus autores, falla precisamente la motivación en aquella parte que, sin duda, es la más importante y constituye en muchos casos el tema único sobre el que versa el debate» (Delgado García). O la de la misma Sala (Soto Nieto, 20 de febrero de 1991), donde se llama también la atención expresamente sobre el relieve de la «motivación fáctica de la sentencia, al hallarse íntimamente conectada con la presunción de inocencia».

Lo malo es que tal énfasis en la exigencia de motivación fáctica se reserva exclusivamente para la llamada prueba indirecta.

${ }^{116}$ Cfr. M. Taruffo, «La fisonomia», cit., pp. 457; para una más amplia consideración: La motivazione, cit., pp. 437 y ss.

${ }^{117}$ Por todas, las sentencias del Tribunal Constitucional 174 y 175 de 1985 y 14 y 122 de 1991. También el mismo Tribunal Constitucional ha dado vía libre a la motivación por remisión, versión actualizada del castizo «por sus propios fundamentos» (Autos 688 / 1986 y 956 / 1988; y sentencia 27 / 1992). 
tratándose de supuestos 
de la llamada prueba «directa ${ }^{118}$.

No resulta difícil adivinar que la renuncia -ésta quizá más que implícita- a dar realidad en la práctica a exigencias de principio como la que nos ocupa, que, por otra parte, se formulan con tanta firmeza, responde a criterios inequívocamente pragmáticos ${ }^{119}$. Lo malo es que la renuncia no es, como parece querer sugerirse, (solo) a la expresión de la motivación, sino a la motivación misma.

En efecto, aunque en una consideración superficial tal vez cupiera pensar que, en casos como los comprendidos en esa fórmula, habría todo lo más cierta tolerancia con la reserva para el propio órgano decisor de los motivos de su opción acerca de la quaestio facti, no es así.

La exigencia ${ }^{120}$ de trasladar a terceros los (verdaderos) motivos

${ }^{118}$ La contraposición entre prueba «directa» y prueba «indirecta» procede de Bentham (op. cit., vol. I, p. 27). La distinción es cuestionada por Ferrajoli, a partir del criterio de demarcación, porque «las pruebas recogidas en un proceso no son casi nunca directas sino casi siempre pruebas indirectas». De este modo, «si se excluyen los delitos cometidos durante un juicio, en los que el hecho probatorio y el hecho objeto de prueba son todo uno, las pruebas directas no existen» (Ferrajoli, op. cit., p. 110 y p. 164, n. 25). Hay que decir que, seguramente, las pruebas no serían directas en ese sentido ni siquiera en este último caso; en el que el enjuiciamiento del eventual delito resultaría transferido a otro tribunal, ante el que los magistrados que presenciaron el hecho incriminable tendrían que declarar como testigos.

119 Son los mismos que se expresan en una marcadísima tendencia jurisprudencial -generalizada en toda clase de instancias- a recuperar, relegitimándolas por distintas vías, informaciones policiales connotadas de ilegalidad por el quebrantamiento de normas imperativas. Quizá uno de los casos más llamativos esté en el tratamiento de las infracciones del art. 569,4 de la Ley de E. Criminal en no pocas sentencias de la Sala segunda a pesar de lo diáfano de su expresión acerca de la presencia del secretario judicial en los registros, en la versión de 1882, ¡ay!, ya no vigente.

No resulta difícil adivinar en el fondo de estas actitudes la consideración de tales supuestos sub specie de un presunto conflicto entre el ius puniendi del Estado -derecho de la sociedad a defenderse, se dice también- y un cierto interés (exclusivo) del imputado que buscaría beneficiarse arteramente de la aplicación de las garantías. Cuando lo cierto es que, el interés en la efectiva vigencia de éstas es de carácter público-constitucional y se orienta precisamente a la defensa y subsistencia de la sociedad como sociedad democrática.

${ }^{120} \mathrm{La}$ exigencia se entiende, naturalmente, como modelo-límite y apunta a la instalación en el juez-intérprete de una tensión hacia la transparencia; y, al mismo tiempo, a tratar de impregnar su actividad decisora de una cierta distancia autocrítica. Si esta actitud se predica como necesaria para el científico, cuyo hacer tiene que ver con entidades y magnitudes mucho más objetivas, con cuánto más motivo no ha de serlo para el juez, habida cuenta del alto nivel de implicación que es inherente a las 
de la decisión, lejos de resolverse en una simple exteriorización formal de éstos, retroactúa sobre la propia dinámica de formación de la motivación ${ }^{121}$ y de la misma resolución en todos sus planos; obligando a quien la adopta a operar, ya desde el principio, con unos parámetros de racionalidad expresa y de conciencia autocrítica mucho más exigentes ${ }^{122}$. Y es que, efectivamente, no es lo mismo resolver conforme a una corazonada ${ }^{123}$, que hacerlo con criterios idóneos para ser comunicados. Sobre todo en un sistema procesal que tiene al principio de presunción de inocencia como regla del juicio ${ }^{124}$. Regla que tantas veces obliga a resolver contra la propia convicción moral, cuando, después de un cuidadoso análisis de la prueba, aquélla no encuentra confirmación plausible en ésta.

Por eso, aunque en los casos de esa falta de motivación que se designa como motivación implícita, la que más padece es en apariencia la dimensión extraprocesal del precepto del art. 120,3 de la Constitución, la verdad es que el alcance de la claudicación es bastante mayor.

cuestiones morales, y de lo difícil que resulta filtrar los presupuestos ideológicos, religiosos, culturales en general, desde los que inevitablemente se actúa.

${ }^{121}$ «Cuando en efecto la persona que realiza una opción sabe que tiene que motivar (y es la situación típica en que se encuentra el juez), no puede prescindir completamente de tal obligación y por tanto ya se encuentra el campo de las soluciones eventuales restringido al de las opciones racionalmente justificables: se vería constreñido a rechazar una determinada opción, quizá conforme a sus principios, cuando no fuese capaz de argumentarla favorablemente» (G. Ubertis, op. cit., pp. 53-54). (Cursiva mía).

${ }^{122}$ Lo vio muy bien J. Frank cuando escribía: «creo que hará mucho bien exigir la publicación de los fundamentos, aunque no constituye un panacea, porque el mismo acto de escribir su versión de los hechos tiende a inducir al juez a escudriñar y criticar cuidadosamente sus motivaciones y a confrontar sus creencias...» (op. cit., p. 97).

También E. Döhring cuando escribe: «un benéfico constreñimiento al autocontrol es el que impone el deber del averiguador profesional de justificar sus hipótesis por escrito»; algo que es válido «muy en especial para el juez, que tiene que fundamentar circustanciadamente en la sentencia su concepción del estado de los hechos» (La investigación del estado de los hechos en el proceso. La prueba, su práctica y apreciación. Trad. de Tomás A. Banziaf, Ejea, Buenos Aires, 1986, p. 451).

${ }^{123} \mathrm{~J}$. Fernández Entralgo ha recordado oportunamente lo «fácil que es ceder a la tentación de primar la intuición a costa de fabricar una verdad de artificio adaptada a aquélla, que más tarde se invocara para pretender mantener intangible el resultado de una tal manipulación» («Presunción de inocencia, apreciación de la prueba y motivación de la sentencia», en Revista General de Legislación y Jurisprudencia, n. 493-494, p. 3.142).

${ }^{124}$ Tomo la expresión de G. Illuminati, La presunzione d'innocenza dell'imputato. Zanichelli, Bolonia, 1979, pp. 163-165). 
Motivar, escribe Gianformaggio, «significa justificar, y justificar significa justificarse, dar razón del propio trabajo admitiendo en 
línea de principio la legitimidad de las críticas potenciales, la legitimidad de un control» ${ }^{125}$. Efectivamente, la exigencia de motivación responde a una finalidad de control del discurso, en este caso probatorio, del juez, con objeto de garantizar hasta el límite de lo posible la racionalidad de su decisión, en el marco de la racionalidad legal ${ }^{126}$. Un control, por cierto -conviene insistir-, no sólo de procedencia externa, sino que no puede carecer de esa proyección interna sobre el propio operador a la que nos hemos referido ${ }^{127}$; y cuyo fin es, como se ha visto, implicarle (complicarle, diría) o comprometerle, para evitar la aceptación acrítica, como convicción, de alguna de las «peligrosas sugestiones de la "certeza subjetiva" $\gg{ }^{128}$. Esto, incluso en el caso hipotético de que toda la actividad probatoria fuera de la llamada directa ${ }^{129}$. Porque esa difícil eventualidad (donde además directa no significa necesariamente simple) nunca excluiría aquel peligro y por ende no podría autorizar al juez a rebajar el nivel de la racionalidad exigible en su trabajo; y porque, en cualquier caso, la sentencia no dejaría de estar dirigida a terceros, a toda la sociedad, que es lo que impone que se le dote de la información necesaria para que resulte un texto autosuficiente, que «se baste a sí misma ${ }^{130}$, sin necesidad de remisiones a las actas del proceso.

Por eso no me parece aceptable el punto de vista de Ruiz

${ }^{125}$ L. Gianformaggio, op. cit., p. 136.

${ }^{126}$ «El control de la toma de decisión judicial en el área determinada por las normas legales es un postulado de todo sistema que se base en el principio de legalidad» (J. Wrobleswski, Sentido y hecho en el derecho. Trad. de J. Igartua y J. Ezquiaga, Universidad del País Vasco, San Sebastián, 1989, p. 238). En esa línea las normas jurídicas son calificadas como «factores de restricción de los márgenes de la decisión» (p. 235).

127 J. Fernández Entralgo ha hecho hincapié en la «función preventiva» de la obligación impuesta al juez de «depurar su propio discurso, en una labor autocrítica, que constituirá, sin lugar a dudas, la mejor profilaxis contra posibles quebrantamientos del derecho a la presunción de inocencia» ( «La motivación de las resoluciones judiciales en el proceso penal: doctrina del Tribunal Constitucional», en Poder Judicial, número especial IV, dedicado a «Protección jurisdiccional de los derechos fundamentales y libertades públicas,» p. 71).

${ }^{128}$ F. Stella, Leggi scientifiche e spiegazione causale nel diritto penale. Giuffrè, Milán, 1990, p. 155. En idéntico sentido M. Nobili: «certeza moral no debe significar nunca arbitrio, sino conocimiento razonado» (La formazione..., cit., p. 281).

${ }^{129}$ J. Fernández Entralgo ha puesto de relieve cómo no existe argumento válido, para limitar el alcance del deber de motivar a los supuestos en que la convicción se apoya en prueba indiciaria, cuando lo que está en juego es «la efectividad de un derecho fundamental». (En «La motivación de las resoluciones...», cit., p. 76).

${ }^{130}$ Tomo la expresión de J. B. Maier, Derecho Procesal Penal Argentino. 1 b Fundamentos. Hammurabi, Buenos Aires, 1989, p. 593. 
Vadillo que no cree «obligado ni necesario» que el juez o el tribunal hagan un examen exhaustivo de la prueba y expliquen el porqué de la relevancia dada a cada medio en concreto: «por qué (se) creyó a dos testigos y (se) dejó de creer a tres o por qué (se) dio más credibilidad a un informe pericial que a otro». Encuentra el autor la justificación de este criterio en que «en un tribunal colegiado (...) no todos sus miembros en su intimidad llegan a la conclusión de la culpabilidad y, por tanto, a la credibilidad de una prueba frente a otra, por el mismo camino y con idéntico recorrido, y no (sabe) cómo habría de redactarse la sentencia condenatoria en estos casos»; y, asimismo, en que «no parece conveniente ni menos necesario subrayar la incredibilidad de un testigo o de varios de manera expresa. $\mathrm{Ni}$ siquiera es fácil explicar por qué se inclinó un juez por uno u otro testimonio». De ahí que estime suficiente que se «deje constancia de los datos de que se ha dispuesto, declaraciones a favor o en contra, pericias en uno y otro sentido, etc., y cómo a su través, con prueba inequívoca de cargo, se llegó a la condena». Porque «lo importante es decir cuáles son los hechos inequívocamente probados, y de ellos obtener la correspondiente conclusión» ${ }^{131}$.

Como se ha escrito en ocasiones, cada modo de sentenciar, como cada manera de escribir, lleva consigo una implícita selección del destinatario, del interlocutor. Desde esta perspectiva, diría que la propuesta de Ruiz Vadillo acota como espacio de diálogo sólo el estrictamente intraprocesal. Y lo hace en términos que se sitúan incluso por debajo del nivel de exigencia del art. 10,6a de la Ley Orgánica 10 / 1980, de 11 de noviembre, que imponía al juez el deber de plasmar «de manera expresa las pruebas practicadas y su resultado», es decir, el rendimiento de cada una de ellas. Y más lejos aún de la prescripción de la regla segunda del art. 85,2 de la Ley Procesal Militar, que, después de establecer la necesidad de consignar en la sentencia los hechos que se estimen probados, impone «la fundamentación de dicha convicción».

En ambos casos se quiere algo más que el simple «dejar constancia de los datos», se pide al juez que razone el valor probatorio atribuido a cada uno de ellos. La «exteriorización del porqué de las conclusiones de hecho», al decir de Maier ${ }^{132}$.

No basta con que el juez afirme que tiene (para sí) una convicción, debe exponerla para compartirla. Diría incluso que en la misma idea de conferir a un resultado probatorio por sí

${ }^{131}$ E. Ruiz Vadillo, «Hacia una nueva casación penal», en Boletín de Información del Ministerio de Justicia, n. 1.585 , p. 5.685.

132 J. B. J. Maier, op. cit., p. 244. 
mismo existencia objetiva como «de cargo» hay algo de falaz. Porque lo que, en definitiva, lo constituye como tal es la atribución de una determinada valencia, dentro de un tejido de elementos de juicio en relación de mutua implicación.

Se advierte con claridad en el caso del voto disidente en un tribunal colegiado, que muy bien puede partir de los mismos datos probatorios que la resolución de mayoría, pero, eso sí, entendidos de una manera diversa. Modo de entender discrepante, que nunca podría proyectarse hacia afuera del órgano como un simple porque sí. Como parece que tampoco podría hacerlo la misma resolución que motiva el disentimiento y, en suma, ninguna resolución.

Cierto que puede haber casos de esos en los que, coloquialmente, se dice, los hechos se explican por sí solos, pero esto realmente nunca es así: el juicio de hecho será más o menos elemental, pero no podrá dejar de producirse. Por otro lado, no conviene olvidar que el mandato constitucional es incondicionado, y que las resoluciones judiciales, que con harta frecuencia ilustran acerca de vicisitudes procesales inútiles desde el punto de vista de la economía de la justificación, suelen ser extraordinariamente parcas al recoger los datos que podrían dar cuenta de la forma en que se ha producido efectivamente la contradicción en el acto de la vista. Con ello resulta que si, generalmente, la sentencia penal rara vez es comprensible para quien no conozca los antecedentes de la causa, al ocultarse el nudo de la decisión, puede muy bien resultar un jeroglífico, incluso para las partes. Cuando lo cierto es que, como se ha dicho, la Constitución ha optado por hacer de ella un texto inteligible y, Perelman diría, convincente ${ }^{133}$ incluso para alguien que lo lea desde fuera de la relación procesal concreta.

Hay un dato, el de la dificultad de la auténtica motivación, también señalado por Ruiz Vadillo, que no puede dejar de reconocerse como cierto. Porque «motivación», en el expresivo decir de Cordero ${ }^{134}$, significa «máquina dialéctica», ejercicio de una «función ostensiva (que) disuelve los arcana iustitiae» llevándose con ellos -al menos tendencialmente- una forma siempre más cómoda de ejercicio de la jurisdicción.

Desde luego motivar, como cualquier acto de racionalidad explícita, no puede ser fácil. Pero, ¿no será precisamente en esa dirección donde apunta el imperativo constitucional? Porque, en

${ }^{133}$ Cfr. Ch. Perelman, La lógica jurídica y la nueva retórica. Trad. de L. Diez Picazo, Civitas, Madrid, 1979, p. 213.

${ }^{134}$ F. Cordero, «Stilus curiae...», cit., pp. 302 y 306. 
efecto, en la genealogía de todos los controles democráticos sobre los actos de poder, late el propósito de hacer su ejercicio racionalmente justificado, es decir, más difícil, pero también más legítimo ${ }^{135}$. Por eso tiene que ser necesariamente más difícil la función del juez en un modelo informado por el principio de legalidad que en el de la «justicia del cadí»».

También es verdad que el nivel de dificultad en la elaboración del discurso motivador puede crecer en el caso de los tribunales colegiados, pero quizá ello responda asimismo a la lógica interna del propio sistema, que les atribuye generalmente la resolución de los casos más complejos o de mayor trascendencia y el reexamen de lo actuado por otros órganos. En ellos la garantía radica, precisamente, en que la formación de la conciencia y la voluntad colectiva vaya más allá de la mera yuxtaposición de «intimidades», para convertirse en una verdadera convicción a trois (cuando son tres los magistrados que forman la sala, naturalmente).

\section{CASACIÓN: JUZGAR EL JUICIO DE HECHO}

Como bien se sabe, y para decirlo con palabras ya clásicas entre nosotros, «limítase la casación, partiendo de los mismos hechos fijados en la sentencia, a examinar la concepción jurídica causal del fallo, o bien, desentendiéndose del sentido de éste, la regularidad del proceder que haya conducido hasta él» ${ }^{136}$.

Este punto de vista, con carta de naturaleza en el tratamiento tradicional de la casación, responde a la misma filosofía que impregna una de las formas de entender la libre convicción judicial.

Si ésta se concibe como un ejercicio de la más absoluta intimidad, como una experiencia intraducible, como una suerte de momento pánico, ello no puede más que llevar consigo la imposibilidad asimismo absoluta de volver sobre él para intentar su comprensión desde fuera.

Pero ya hemos visto que esto no es ni ha sido nunca objetivamente así, aunque la intime conviction haya recibido en ocasiones ese tratamiento, que aún cuenta con partidarios.

El proceso de adquisición de conocimiento del juez no es estructural mente más ni menos complejo que otras formas del razonar.

Por otra parte, recuerda Cordero, el «hermetismo togado» es

135 «La "razón de" ya no es entonces solamente algo que explica, sino que legitima» (P. Ricoeur, op. cit., p. 52).

${ }^{136}$ E. Gómez Orbaneja-V. Herce Quemada, op. cit., p. 260. 
históricamente muy anterior a la acunación de la convicción íntima como principio: «también los doctores italianos recomiendan reticencia: nunca exprimere causam»; porque «justicia oculta, jueces omnipotentes» ${ }^{137}$.

Precisamente por eso, en una concepción tendencialmente democratizadora del proceso como la que expresa nuestro texto constitucional, hay que entender que a la falta de obstáculos de índole gnoseológica, se añade una consistente razón política para profundizar, por la vía del control jurisdiccional, en la exigencia de la motivación.

En esa línea, una de las convenciones que resulta preciso combatir es la que tiende a recluir todo el componente lógico del juicio en el de derecho», ${ }^{138}$ como si no existiera otra lógica que la deductiva: lo que sería, en fin, una forma más de insistir en la atribución de una inadmisible carga de irracionalidad al razonamiento del juez.

A este «prejuicio epistemológico» se ha referido Ferrajoli, apuntando la alternativa: «es claro que si, al contrario, por lógica» se entiende la lógica no sólo deductiva, sino también inductiva, no hay razón para no admitir el control lógico de la casación también sobre la adecuación de la motivación en materia de hecho, es decir, sobre la carencia de confirmaciones (o pruebas) por modus ponens o sobre la presencia o no experimentación de contrapruebas por modus tollens» ${ }^{139}$.

Con todo, lo cierto es que el control casacional del modo de aplicación de las máximas de experiencia -aunque sea limitado a los supuestos más llamativos- se ha abierto camino en experiencias comparadas, regidas como la española, por la previsión del exclusivo control de la transgresión legal. Tal es el caso de la jurisprudencia alemana y de la italiana.

Como señala Walter, «hay quienes ven realizado en la práctica de los tribunales de casación el principio de que también pueden ser sometidas al control de esa instancia las comprobaciones de hechos (en virtud de la fórmula de "las transgresiones de las leyes del razonamiento y de la experiencia, de las constataciones poco claras y lagunosas")» ${ }^{140}$.

${ }^{137}$ F. Cordero, «Stilus curiae..» cit., pp. 302-303.

${ }^{138}$ Así G. Calogero, para quien, mientras en el juicio de derecho el carácter ilógico del juicio se confundiría con la «antijuridicidad», que no escapa al control de la casación, el mismo vicio referido al juicio de hecho sería un error defacto del propio juicio de hecho, por sí mismo incensurable en casación (en op. cit., p. 5).

${ }^{139}$ L. Ferrajoli, op. cit., pp. 179-180, n. 83.

${ }^{140}$ G. Walter, op. cit., p. 350. 
En este punto de vista hay implícito un replanteamiento del sentido de la convicción íntima, que, ciertamente, no podría estar sometida a patrones legales de valoración del material probatorio. Pero que no puede dejar de respetar las reglas del discurso racional. Por eso, concluye Walter señalando cómo «la observancia de las leyes del razonamiento no constituye un límite de la apreciación de la prueba, sino que es inmanente a ésta. O mejor dicho, cuando se trata de la observancia de leyes del razonamiento, no hay lugar para una apreciación» ${ }^{141}$.

En el mismo sentido, y de forma bien plástica, se ha expresado Cordero, con respecto a Italia, al hacer notar la vigencia práctica de un cierto control del uso de las máximas de experiencia. De no ser así, dice, «cualquier conclusión delirante sería invulnerable. Por ejemplo, $\mathrm{N}$ resulta condenado a partir de la siguiente premisa: es uno de los siete que pueden haber matado a P; y le odiaba, al contrario que los otros; es imposible que pueda haber resistido el impulso; quien odia de esa manera no pierde cómodas ocasiones de matar» ${ }^{142}$.

La consolidación de ese punto de vista exige el definitivo desplazamiento de una viciosa concepción circular sobre el papel del principio de inmediación en la formación de la convicción.

La inmediación es, qué duda cabe, una garantía, pero sólo de carácter instrumental, preordenada a hacer posible a partir del contacto directo, una valoración racional de los actos probatorios, que pueda a su vez ser racionalmente enjuiciada por terceros.

Por el contrario, cuando la inmediación se usa -y es frecuente- como barrera para vetar el acceso al examen del curso valorativo del juez o tribunal, se convierte en una injustificable coartada, primero para propiciar que el juez oculte sus razones; y, después, para negar legitimidad a cualquier tentativa de fiscalizarlas.

Así resultará que la inmediación, que por sí misma no es necesariamente un obstáculo frente al proceder arbitrario del juez, puede convertirse en paradójica garantía de discrecionalidad judicial incontrolada.

Para que no sea así, se hace preciso acabar con la confusión, bien patente en la opinión de Calogero, antes citada, de que prueba y quaestio facti son la misma cosa. Porque, como escribe Ferrajoli, debe distinguirse entre el juicio sobre el hecho y el juicio sobre el juicio. Y dentro de éste, «es claro que el juicio sobre la motivación forma un todo con el

${ }^{141}$ G. Walter, op. cit., p. 355.

${ }^{142}$ F. Cordero, Procedura, ed, 1991, cit., p. 936. 
juicio de legalidad; y que el 
control sobre la consistencia (no de las pruebas sino) del razonamiento probatorio, es todo uno con las garantías de legalidad que expresan los tres clásicos brocardos nulla poena sine crimine, nullum crimen sino lege y nulla poena et nullum crimen sino iuditio ${ }^{143}$.

Este modo de entender la cuestión se encuentra en alguna resolución de la Sala Segunda. Así la de 15 de abril de 1989 (ponente Bacigalupo Zapater) que declara controlable en casación el que califica de «segundo nivel de valoración judicial», que es el relativo «a las deducciones e inducciones que el tribunal puede realizar a partir de los hechos que ha percibido directamente en el juicio oral. Estas inferencias pueden ser controladas en la casación precisamente porque no dependen sustancialmente de la inmediación, sino de la corrección del razonamiento que se debe fundar en las reglas de la lógica, en los principios de la experiencia y, en su caso, en conocimientos científicos. Por tanto, en la medida en que el tribunal de casación tiene completo acceso a ese razonamiento puede verificar en cada caso la corrección de las conclusiones»».

La doctrina, desde luego impecable, tiene además la virtud de poner a la propia Sala Segunda ante un reto: franquearse ella misma, a través de la exigencia de la motivación explícita del juicio de hecho, el «completo acceso a ese razonamiento», que, hoy por hoy, le cierra, sin consecuencias, cualquier tribunal que reserve para sí los criterios de valoración tenidos en cuenta. Y no digamos cuando se trata de la dichosa prueba directa.

El concepto de motivación en sentido fuerte, que constituye el antecedente necesario de un control casacional como el que justifica la sentencia que acaba de citarse, tiene inequívoco apoyo normativo del más alto rango.

En efecto, está la exigencia del art. 120,3 de la Constitución. Aunque la colocación sistemática del precepto es un obstáculo para que su inobservancia permita el acceso al recurso de amparo, parece que en todo caso ésta habría de tener encaje en el supuesto del art. 849.1 de la Ley de Enjuiciamiento Criminal, máxime si se le relaciona con la previsión del art. 5,4 de la Ley Orgánica del Poder Judicial; salvo que pueda entenderse que el dictado constitucional en este punto carece de «carácter sustantivo» y / o no deba «ser observado en la aplicación de la ley penal».

${ }^{143}$ L. Ferrajoli, «I valori del doppio grado e delta nomofilachia», en Il giudizio di Cassazione nel sistema delle impugnazioni, en Materiali e atti del Centro Studi per la Riforma dello Stato. Suplemento al n. 1, enero-marzo 1992, de Democrazia e Diritto, pp. 34 y 40-41. 
Pero, en último término, el defecto de motivación siempre tendría, como entiende Bacigalupo $^{144}$, las consecuencias de producir indefensión, relevante a los efectos del art. 24 $\mathrm{CE}$, y de encarnar una forma de ejercicio arbitrario de un poder público, de las proscritas en el art. 9,3 CE. Esto, creo, no sólo en el caso de motivación incorrecta, sino también en el de pura y simple falta de expresión de la motivación.

Entenderlo de otro modo, supone la aceptación práctica del hecho de que el juez puede situarse potestativamente por encima de un deber constitucional, inequívocamente impuesto. Y también perder de vista que, más allá de consideraciones pragmáticas o de oportunidad y de eventuales costes coyunturales, el instrumento de la declaración de nulidad tiene, trascendiendo el caso concreto, una ratio. Ésta consiste en asegurar la capacidad ordenadora del orden jurídico $\mathrm{y}$, en consecuencia, demanda de quienes tienen la responsabilidad de hacerla efectiva que se le dote, como es de ley, de una eficacia generalizada. Ello aquí significa dejar claro cómo hay que hacer las cosas, es decir, las sentencias. Si se quiere que definitivamente se ajusten al único modelo posible en este caso: el constitucional.

${ }^{144}$ E. Bacigalupo Zapater, «La impugnación de los hechos probados en el recurso de casación penal. (Reflexiones sobre un decenio de aplicación del art. 24,2 CE)», en curso de publicación, consultado en la versión mecanográfica. 
DOXA-12 (1992) 